\title{
Effects of Nanotopography Regulation and Silicon Doping on Angiogenic and Osteogenic Activities of Hydroxyapatite Coating on Titanium Implant
}

This article was published in the following Dove Press journal: International Journal of Nanomedicine

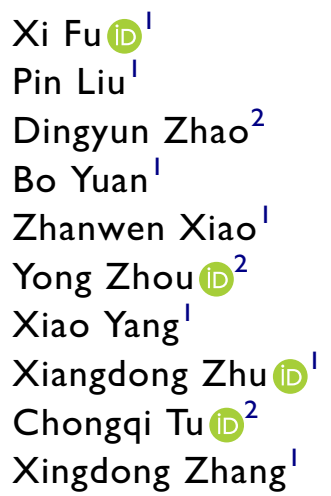

'National Engineering Research Center for Biomaterials, Sichuan University, Chengdu 610064, People's Republic of China; ${ }^{2}$ Department of Orthopaedics, West China Hospital of Sichuan University, Chengdu 61004I, People's Republic of China
Correspondence: Xiangdong Zhu National Engineering Research Center for Biomaterials, Sichuan University, No. 29 Wangjiang Road, Chengdu 610064, People's Republic of China

Tel +8628 85470770

Email zhu_xd1973@scu.edu.cn

\section{Chongqi Tu}

Department of Orthopaedics, West

China Hospital of Sichuan University, No.

37 Guo Xue Xiang, Chengdu 6I004I,

People's Republic of China

Tel +862885422570

Email tcqbonetumor@।63.com
Background: Angiogenic and osteogenic activities are two major problems with biomedical titanium (Ti) and other orthopedic implants used to repair large bone defects.

Purpose: The aim of this study is to prepare hydroxyapatite (HA) coatings on the surface of Ti by using electrochemical deposition (ED), and to evaluate the effects of nanotopography and silicon $(\mathrm{Si})$ doping on the angiogenic and osteogenic activities of the coating in vitro.

Materials and Methods: HA coating and Si-doped HA (HS) coatings with varying nanotopographies were fabricated using two ED modes, ie, the pulsive current (PC) and cyclic voltammetry $(\mathrm{CV})$ methods. The coatings were characterized through scanning electron microscope (SEM), X-ray diffraction (XRD), Fourier transform infrared spectroscopy (FT-IR), X-ray photoelectron spectrometer (XPS), and atomic force microscopy (AFM), and their in vitro bioactivity and protein adsorption were assessed. Using MC3T3-E1 preosteoblasts and HUVECs as cell models, the osteogenic and angiogenic capabilities of the coatings were evaluated through in vitro cellular experiments.

Results: By controlling Si content in $\sim 0.8$ wt. $\%$, the coatings resulting from the PC mode (HA-PC and HS-PC) and CV mode (HA-CV and HS-CV) had nanosheet and nanorod topographies, respectively. At lower crystallinity, higher ionic dissolution, smaller contact angle, higher surface roughness, and more negative zeta potential, the HS and PC samples exhibited quicker apatite deposition and higher BSA adsorption capacity. The in vitro cell study showed that Si doping was more favorable for enhancing the viability of the MC3T3-E1 cells, but nanosheet coating increased the area for cell spreading. Of the four coatings, HS-PC with Si doping and nanosheet topography exhibited the best effect in terms of up-regulating the expressions of the osteogenic genes (ALP, Col-I, OSX, OPN and OCN) in the MC3T3-E1 cells. Moreover, all leach liquors of the surfacecoated Ti disks promoted the growth of the HUVECs, and the HS samples played a more significant role in promoting cell migration and tube formation than the HA samples. Of the four leach liquors, only the two HS samples up-regulated NO content and expressions of the angiogenesis-related genes (VEGF, bFGF and eNOS) in the HUVECs, and the HS-PC yielded a better effect.

Conclusion: The results show that $\mathrm{Si}$ doping while regulating the topography of the coating can help enhance the bone regeneration and vascularization of HA-coated Ti implants.

Keywords: electrochemical deposition, hydroxyapatite, silicon, coating, morphology, MC3T3-E1 cells, HUVECs

\section{Introduction}

Titanium (Ti) and its alloys have been widely applied to the treatment of clinical bone defects at load-bearing sites of the body because of their excellent mechanical properties, resistance to corrosion, and biocompatibility. ${ }^{1}$ However, Ti metal is biological inert, 
because of which effective osteointegration with the host bone after implantation is challenging when using it. ${ }^{2}$ In addition, the passivation film on the surface of Ti can easily dissolve or peel under long-term stimulation due to stress and the erosion of body fluid, which results in the loosening and failure of the implant. ${ }^{3}$ To solve these problems, a variety of methods of surface modification or activation have been developed to improve the biological properties of Ti implants, and have yielded promising outcomes.

Plasma spraying hydroxyapatite (HA) coating has been used in the clinic for decades, and has played a positive role in improving the osteointegration-related capability of $\mathrm{Ti}$ implants. ${ }^{4,5}$ Other methods to prepare HA coatings on the surface of Ti have also been proposed, such as biomimetic mineralization, sol-gel, and electrophoretic or electrochemical deposition (ED).$^{6-9}$ In recent years, 3D printing and other technologies to fabricate porous metal scaffolds have developed rapidly, and are considered useful strategies to solve the problem of the stress shielding of Ti implants. ${ }^{10}$ The linear processing mode of plasma spraying is unsuitable for fabricating an HA coating on porous implants with complex structures. Such liquid-based methods as ED therefore present advantages owing to their non-linear processing, and the adjustable morphology and thickness of the coating. 9,11 Our recent investigations also indicate that HA nanoparticles and the resulting coating can enhance the osteogenic capability of porous implants. ${ }^{12,13}$

Vascularization is considered among the important factors influencing the repairing of large bone defects. Blood vessels play a key role in transporting nutrients and maintaining the normal metabolism of the tissue. ${ }^{14}$ If blood supply is inadequate, newly formed tissue in bone scaffolds is unlikely to survive for long. ${ }^{15}$ Therefore, it is quite important for a biomaterial scaffold to have good osteogenic and angiogenic activities.

Silicon ( $\mathrm{Si}$ ), as an indispensable trace element in organisms, has a significant positive effect on osteogenesis and angiogenesis. It has been reported that $\mathrm{Si}$ can increase the content of the extracellular matrix, polysaccharides, hydroxyproline, total protein, and collagen to promote osteogenesis. $^{16}$ Furthermore, it can improve osteogenic activity by regulating immunity. ${ }^{17}$ Research has shown that the addition of Si to bioactive scaffolds can enhance communication between HUVECs and BMSCs, which is beneficial for activating the downstream signals of osteogenic and angiogenic pathways. ${ }^{18}$ Therefore, introducing $\mathrm{Si}$ to bioactive HA can help enhance the osteogenic and angiogenic properties of Ti implants. Si-doped HA (HS) bioceramics have been widely investigated, ${ }^{19}$ but few studies have examined coating technology. Moreover, most relevant work has focused on the role of Si itself, and has ignored the resulting synergistic effects when it is used with other physicochemical properties of biomaterials.

In previous research, we fabricated a layer of homogeneous HA coating with needle-like morphology on the surface of a porous Ti scaffold using an ED method. ${ }^{20}$ In this study, two ED modes, ie, cyclic voltammetry (CV) and pulsed current $(\mathrm{PC})$, are used to fabricate HA and HS coatings on Ti disks. The Si content and morphology of the coatings were successfully regulated by adjusting the processing parameters. To explore whether the HS coating influenced osteogenesis and angiogenesis, in vitro cellular experiments using MC3T3E1 pre-osteoblasts and HUVECs as models were carried out on the surface-coated Ti disks. The results show that the ED method can be used to prepare nanosheet HS coating on the surface of Ti to endow it with good osteogenic and angiogenic activities. This is promising for use in biomedical applications.

\section{Materials and Methods Preparation of ED Coating on Ti Disks}

The experimental procedure used in this study is shown in Figure S1. Ti disks $\left(\Phi 14 \times 1 \mathrm{~mm}^{3}\right)$ were machined from a pure, commercial Ti rod, and were surface-polished by using metallographic abrasive papers. The disk samples were cleaned with petroleum ether, acetone, ethanol, and deionized water to remove surface grease under ultrasonic conditions, followed by acid and alkali (AA), and ED treatments.

For the AA treatment, the samples were subjected to a processing procedure proposed in the literature. ${ }^{21}$ They were successively treated in a mixing solution of $\mathrm{H}_{2} \mathrm{SO}_{4}$, $\mathrm{HCl}$, and deionized water $\left(\mathrm{d}-\mathrm{H}_{2} \mathrm{O}\right)$ at a ratio of $1: 1: 2$, and a $6 \mathrm{M} \mathrm{NaOH}$ solution for $2 \mathrm{~h}$ at $70{ }^{\circ} \mathrm{C}$. The AA-treated disks were then subjected to ED treatment. An electrolyte containing $2.5 \mathrm{mM} \mathrm{Ca}^{2+}, 1.2 \mathrm{mM} \mathrm{PO}_{4}{ }^{3-}$, and $0.3 \mathrm{mM}$ $\mathrm{SiO}_{3}{ }^{2-}$ was prepared from $\mathrm{Ca}\left(\mathrm{NO}_{3}\right)_{2} \times 4 \mathrm{H}_{2} \mathrm{O}, \mathrm{NH}_{4} \mathrm{H}_{2} \mathrm{PO}_{4}$, and $\mathrm{Na}_{2} \mathrm{SiO}_{3} \times 9 \mathrm{H}_{2} \mathrm{O}$. ED treatment was carried out in an electrochemical workstation (PARSTAT 2273, Princeton Applied Research, USA). A three-electrode system was used, in which a platinum electrode, a saturated calomel electrode, and the sample were respectively used as the anode, reference electrode, and working electrode. Two modes of deposition were used. One was the CV method, in which the potentials were controlled to between $0 \mathrm{~V}$ and $-2 \mathrm{~V}(5 \mathrm{mV} / \mathrm{s})$. The other was the $\mathrm{PC}$ method, in which the 
densities of the substrate and pulse current were set to 0 $\mathrm{mA} / \mathrm{cm}^{2}$ and $-5 \mathrm{~mA} / \mathrm{cm}^{2}$, respectively. For a cycle, the electrical interruption time and deposition time were set to $1 \mathrm{~s}$ and $10 \mathrm{~s}$, respectively. The processing time of each mode was $20 \mathrm{~min}$, and the temperature was maintained at $85{ }^{\circ} \mathrm{C}$.

The coatings without and with Si doping, prepared by the CV method, were respectively called HA-CV and HS$\mathrm{CV}$. Likewise, the coatings without and with Si doping, prepared using the PC method, were respectively called HA-PC and HS-PC.

\section{Characterization of ED Coating}

The morphology and elemental composition of the coating on the surface of the Ti disks were characterized by using a field emission scanning electron microscope (FE-SEM, S4800, Hitachi, Japan) equipped with an energy-dispersive spectrometer (EDS). For the quantitative analysis of the $\mathrm{Si}$ content of the coating, each sample was dissolved in $5 \mathrm{~mL}$ of $0.1 \mathrm{M} \mathrm{HCl}$, and tested by using an inductively coupled plasma mass spectrometer (ICP-MS, VG PQExCell, TJA, USA). Five parallel samples for each group were used.

The phase composition of the coating was analyzed by thin-film X-ray diffraction (TF-XRD, X' pert pro-MPD, PANalytical, Netherlands), in which a grazing method at an angle of $2^{\circ}$ was used. The crystallinity and lattice constant of the coating were determined by Rietveld refinement and calculated using Jade 6.0 software. The chemical state of elements of the coating and the change in binding energy were examined by an X-ray photoelectron spectrometer (XPS, XSAM800, Kratos, Britain). The excitation power was set to $200-400 \mathrm{~W}$, and vacuum was maintained at $10^{-6}-10^{-7} \mathrm{~Pa}$. Changes in the intensity of the peaks of phosphate and hydroxide absorption in the coating were determined by Fourier transform infrared spectroscopy (FT-IR, Nicolet 6700, TFS, USA). After they had been removed from the coating through ultrasonic oscillation, the deposits were dried, mixed with potassium bromide, and pressed into a wafer for testing in a spectral range of $4000-500 \mathrm{~cm}^{-1}$.

The surface roughness of each surface-coated sample was tested by atomic force microscopy (AFM, MFP-3DBIO, Asylum Research, USA). The test ruler was set to $5 \times 5$ $\mu \mathrm{m}$. Five areas for each surface and three parallel samples for each group were tested to acquire the average value of surface roughness $(\mathrm{Ra})$, which was calculated using IGOR Pro 6 software. The surface wettability of each surfacecoated sample was tested by measuring the contact angle of water (IL4200, KRU“SS GmbH, Germany), and three parallel samples for each group were used. The surface zeta potential of each surface-coated sample $\left(10 \times 10 \times 1 \mathrm{~mm}^{3}\right)$ was measured by a solid zeta potential tester (Surpass, Anton Paar, Austria). Three parallel tests for each sample was performed using a $0.001 \mathrm{M} \mathrm{KCl}$ solution at a $\mathrm{pH}$ of 7.4, and the value of the zeta potential was calculated based on the Smoluchowski equation. ${ }^{22}$

\section{Ion Release Test}

To investigate ion release from the surface coating of each Ti sample, a static immersion test was carried out. Each surface-coated Ti sample was soaked in $2 \mathrm{~mL}$ of serumfree DMEM (Gibco, NY, USA) for three, seven and 14 days after irradiation sterilization. The ionic concentrations of $\mathrm{Ca}, \mathrm{P}$, and $\mathrm{Si}$ in the media at each time point were measured using an inductively coupled plasma-mass spectrometry (ICP-MS, Agilent720, USA).

\section{Bioactivity Test in vitro}

To test the in vitro bioactivity of each surface-coated sample, a simulated body fluid (SBF) immersion experiment was performed according to a method proposed in the literature. $^{23}$ The samples were soaked in SBF for $12 \mathrm{~h}$ and $24 \mathrm{~h}$ at $37^{\circ} \mathrm{C}$, rinsed with deionized water, and then dried at $70{ }^{\circ} \mathrm{C}$. The newly formed deposits on the sample surface were observed through SEM (S4800, Hitachi, Japan).

\section{Protein Adsorption Test}

Bovine serum albumin (BSA) was used as a model protein to investigate the protein adsorption capacity of each sample according to a method that we previously proposed. ${ }^{20}$ Three parallel samples were used for each group. Ten $\mathrm{mg} / \mathrm{mL}$ of BSA in a phosphate-buffered saline (PBS) was prepared in advance. The samples were placed in a 24-well plate, and $1 \mathrm{~mL}$ of the BSA solution was added to each well. After incubation for $2 \mathrm{~h}$ in $37^{\circ} \mathrm{C}$, the samples were taken out and rinsed with deionized water five times. They were then blot dried with filter paper and transferred to another clean plate, and $500 \mu \mathrm{L}$ of $2 \%$ sodium dodecyl sulfonate (SDS) solution was added to them. After incubation in a shaker for $2 \mathrm{~h}$ at $37^{\circ} \mathrm{C}$, the supernatants were collected for quantitative protein analysis $\left(\mathrm{BCA}^{\mathrm{TM}}\right.$ protein assay kit, Pierce, USA) according to the specifications. A total of $200 \mu \mathrm{L}$ of the working solution was added to each well containing $25 \mu \mathrm{L}$ of the supernatants of a 96-well plate, and the mixture was then incubated in an incubator for $30 \mathrm{~min}$ at $37^{\circ} \mathrm{C}$. Absorbance was measured by a multi-function microplate reader (BioTek, EON, USA) at a wavelength of $562 \mathrm{~nm}$. 
Based on the standard curve, the adsorbed BSA on each sample was calculated.

\section{Evaluation of Osteogenic Activity in vitro Cell Culture}

MC3T3-E1 pre-osteoblasts purchased from the Cell Bank of the Chinese Academy of Sciences (Shanghai, China) were used as model to investigate the osteogenic activity of the four surface-coated Ti disks, ie, HA-PC, HS-PC, $\mathrm{HA}-\mathrm{CV}$, and HS-CV. A blank culture plate was used as control. The cell culturing was performed in an incubator at $37{ }^{\circ} \mathrm{C}$ with $5 \%$ of $\mathrm{CO}_{2}$. The seeded cell density of each sample in a 24 -well plate was $2 \times 10^{4}$ cells/well. One $\mathrm{mL}$ of $\alpha$-MEM (Gibco, NY, USA) supplemented with 10\% fetal bovine serum (FBS, Gibco, USA), $100 \mathrm{U} / \mathrm{mL}$ penicillin, and $100 \mathrm{mg} / \mathrm{mL}$ streptomycin were used and renewed every two days.

\section{Cell Viability and Morphology}

The viability of the MC3T3-E1 cells cultured on each sample was evaluated by a cell counting kit-8 assay (CCK-8, Dojindo, Japan). After being cultured for one, three and five days, the samples were taken out and transferred into another 24-well plate, to which $1 \mathrm{~mL}$ of $10 \%$ CCK-8 solution per well was then added. After incubation in the dark for $2 \mathrm{~h}$ at $37^{\circ} \mathrm{C}, 200 \mu \mathrm{L}$ of the supernatant in each well was transferred to a 96-well plate, the absorbance of which was measured by a multi-function microplate reader (BioTek, EON, USA) at a wavelength of 450 nm. The morphology of the MC3T3-E1 cells cultured on each sample was observed by a confocal laser scanning microscope (CLSM, TCS SP 5, Leica Microsystems, Germany). After having been cultured for one, three and five days, the samples were first washed twice with PBS, following which fluorescein diacetate (FDA, Sigma, USA) and propidium iodide (PI, Sigma, USA) were added to them for cell staining. Live cells were stained with green by FDA while dead cells were stained with red by PI.

\section{Cell Spreading}

The spreading morphology of the MC3T3-E1 cells cultured on each sample was observed by CLSM (TCS SP 5, Leica Microsystems, Germany). After having been cultured for one day, the samples were moved to another 24well plate and washed three times with PBS. The cells were then fixed with 4\% para-formaldehyde, washed with $1 \mathrm{~mL}$ of PBS, and stained with rhodamine-phalloidin (5 U/ $\mathrm{mL}$, Biotium, Hayward, CA, USA) and DAPI (Sigma,
USA). The nucleus of each cell was stained with blue through DAPI and its cytoskeleton was stained with red by rhodamine-phalloidin. The area of spreading of the MC3T3-E1 cells on each sample was quantitatively analyzed by using Image Pro Plus 6.0 (Media Cybernetic, USA). For each sample, six randomized non-overlapping fields were selected for analysis.

\section{Osteogenic Gene Expressions}

After being cultured for seven and 14 days, the expressions of the osteogenic genes, including alkaline phosphatase (ALP), collagen I (Col-I), zinc finger structure transcription factor (OSX), osteopontin (OPN), and osteocalcin $(\mathrm{OCN})$ in the MC3T3-E1 cells were analyzed in a real-time quantitative polymerase chain reaction (qRTPCR, CFX96t system, Bio-Rad, USA). The sequences of primers are listed in Table S1. The total RNA of the cells was first extracted with a RNeasy mini kit (Qiagen, Germany), and then transcribed into complementary DNA (cDNA) using iScript cDNA Synthesis Kit (BioRAD, USA). The genes were quantitatively detected by the real-time reverse transcriptase reaction. The expression of each gene was calculated by the relative quantitative $\Delta \triangle \mathrm{CT}$ method, and the results were standardized by GAPDH.

\section{Evaluation of Angiogenic Activity in vitro Cell Culture}

HUVECs obtained from the Mingzhou Biotechnology Company (Ningbo, China) were used as the model to investigate the angiogenic activity of the surface-coated Ti disks, the leach liquors of which in serum-free DMEM (Gibco, NY, USA) were used, at $37{ }^{\circ} \mathrm{C}$ for seven days, for cell culture. One $\mathrm{mL}$ of the leach liquor supplemented with $10 \% \mathrm{FBS}, 100 \mathrm{U} / \mathrm{mL}$ penicillin and $100 \mathrm{mg} / \mathrm{mL}$ streptomycin were used in each well of the 24-well plate and renewed every two days. The other culture conditions were identical to those of the above-mentioned culture of MC3T3-E1 pre-osteoblasts. The above procedure was also used to evaluate the viability and morphology of the HUVECs.

\section{Wound Healing Assay}

The HUVECs $\left(1 \times 10^{4}\right.$ cells/well) were first cultured in a 48 -well plate coated with $0.1 \%$ gelatin, where $500 \mu \mathrm{L}$ of DMEM was added to each well. When the cell confluence reached $90 \%$, a scratch in each well was made by the tip of a $100 \mu \mathrm{L}$ pipette. The culture media were then 
replaced by the serum-free leach liquors to eliminate the effects of cell proliferation. After having been cultured for $12 \mathrm{~h}$ and $24 \mathrm{~h}$, the cells were fixed by $4 \%$ paraformaldehyde and stained with a methylrosanilnium chloride solution. An inverted Asana microscope (ZEISS, DISCOVER V20, Germany) was used to photograph the edge of the scratch-induced wound. Its healing was quantitatively assessed by Image Pro Plus 6.0 (Media Cybernetic, USA), and five non-overlapping regions were selected for each sample.

\section{Angiogenesis in vitro}

The in vitro assessment of angiogenesis was carried out using ECMatrix ${ }^{\mathrm{TM}}$ (Cat. No. ECM625, Millipore, USA). Before the experiment, the plate, $200 \mu \mathrm{L}$ pipettes and the matrix were precooled or dissolved at $4{ }^{\circ} \mathrm{C}$. The matrix was diluted in a serum-free medium in the ratio $1: 1$, and $50 \mu \mathrm{L}$ of the diluted matrix was added to each well of a 96-well plate. After being gelled at $37^{\circ} \mathrm{C}$ for $30 \mathrm{~min}, 50$ $\mu \mathrm{L}$ of the leach liquor containing $1 \times 10^{4}$ cells were added to each well. Then, the cell was fixed by $4 \%$ paraformaldehyde after being cultured for $8 \mathrm{~h}$. The tube-like arrangement of the cells in each well was photographed by the Asana microscope, and the numbers of nodes and junctions, and the lengths of the tube and branch were quantitatively analyzed by Image J (NIH, USA).

\section{NO Staining}

The cells were seeded onto each well of a 96-well plate at a density of $1 \times 10^{4}$ cells/well. After being cultured for five days, the cells were digested and tested using a NO detection kit (Beyotime, China) according to the relevant specifications. The cells were lysed with rapid freeze-thaw, and the supernatants were collected after centrifugation for subsequent analysis. The standard and experimental specimens were added to the plate at $50 \mu \mathrm{L}$ per well. A total of $50 \mu \mathrm{L}$ of Griess Reagent I and Griess Reagent II were then added to each well in the dark. Finally, absorbance of each specimen was measured by a multi-detection microplate reader (BioTek, EON, USA) at a wavelength of $540 \mathrm{~nm}$.

\section{Angiogenesis-Related Gene Expressions}

The PCR analysis of the angiogenesis-related gene expressions was performed according to the above procedure. The gene expressions of vascular endothelial growth factor (VEGF), angiopoietin-1 (Ang-1), endothelial nitric oxide synthase (eNOS), and basic fibroblast growth factor (bFGF) were analyzed. The sequences of primers are also listed in Table S1.

\section{Statistical Analysis}

All statistical results were obtained from the analysis of at least three parallel samples, and were expressed as the mean \pm standard deviation (SD). The data were statistically analyzed using SPSS 11.0 (SPSS Inc, Chicago, USA) at a level of significance of $p<0.05$.

\section{Results \\ Surface Characterization of Surface-Coated Ti Disks}

Figure 1A shows SEM images of surface deposits on the Ti disks prepared using the two ED modes. Both deposits (HA-PC and HS-PC) resulting from the PC method exhibited nanosheet topography, where the nanosheets on HSPC were slightly thinner than those on HA-PC. However, both deposits (HA-CV and HS-CV) obtained from the CV method had a nanorod-like shape, and only HS-CV had the tendency to transform into a nanosheet based on the locally magnified image. Figure 1B shows the elemental mapping of the surface deposits on the Ti disks prepared using the two ED modes. Only Si was detected in both HS samples, and was uniformly distributed in the coating. The results confirm the successful introduction of $\mathrm{Si}$ to the coating, which had little influence on the morphology of the deposits. The Si content of the coating could be easily tailored by adjusting its ionic concentration in the electrolyte. Based on the quantitative analysis of ICP-MS, with increasing ionic concentration of $\mathrm{Si}$ in the electrolyte, its content in the coating first rose rapidly and then tended to reach a saturated value (Figure S2). Under the PC mode, the maximum Si content of the coating was $\sim 0.8 \mathrm{wt} . \%$. But under the $\mathrm{CV}$ mode, it reached above $1.0 \mathrm{wt} . \%$. In this study, both HS samples had identical Si content of $\sim 0.8 \mathrm{wt}$. $\%$, but different coating topographies were used for subsequent tests and evaluations.

Figure 1C shows the ion release curves of the four surface-coated Ti disks after being soaked in serum-free DMEM for 14 days. After three days, the $\mathrm{Si}$ ion release in HS-PC was higher than in HS-CV. But when the soaking time was increased to 14 days, no significant difference was observed between the HS groups. Si doping notably promoted the rates of release of $\mathrm{Ca}$ and $\mathrm{P}$ ions from the coatings. Moreover, the nanosheet coating was more favorable for their rapid release than the nanorod coating.

Figure 2A shows XRD patterns of the surface deposits on the Ti disks prepared using the two ED modes. It is clear that all characteristic peaks of the four samples were in line with 


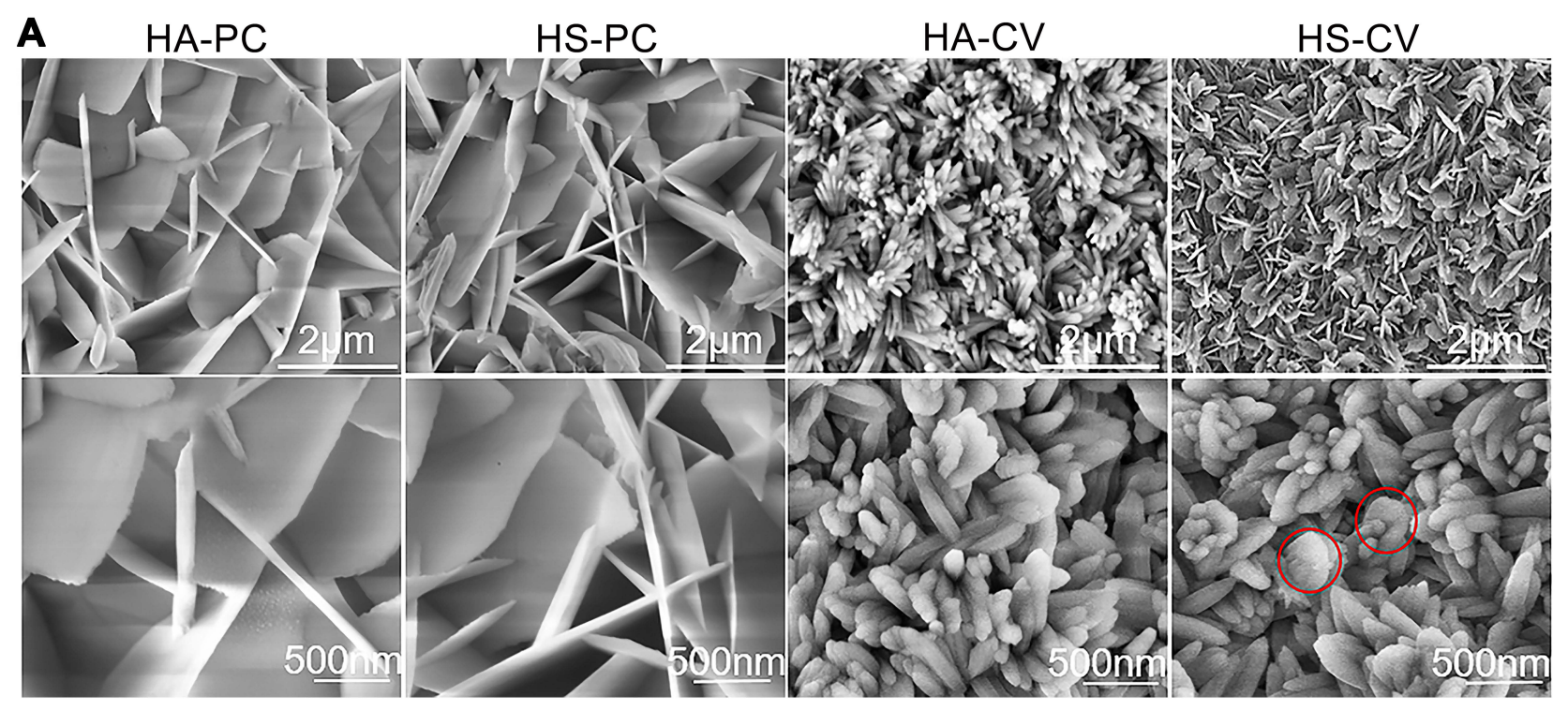

B
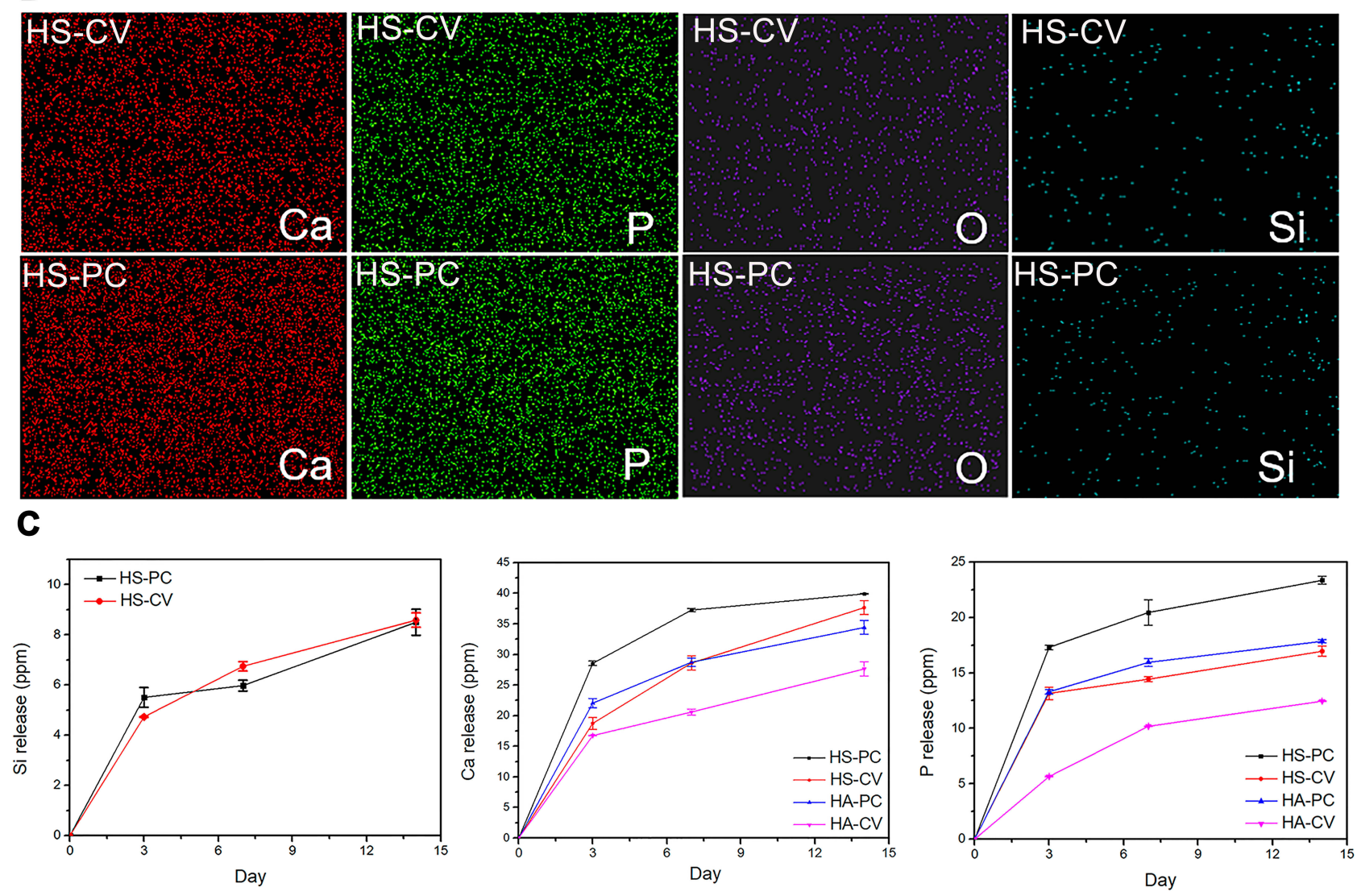

Figure I (A) SEM images of the surface-coated Ti disks (red circles: incomplete separation of the deposited rod-like crystals). (B) Elemental mapping of both HS samples. (C) lonic release curves of both HS samples soaked in serum-free DMEM for different numbers of days $(n=3)$.

those of the standard HA (JCPDS 09-0432), thus confirming that all deposits were composed of the HA phase. The introduction of Si did not cause a change in the phase composition of the deposits. However, compared with the HA samples, the intensities of the characteristic peaks in the HS samples decreased, especially in the (002) direction. This shows that the doped Si can inhibit the preferential growth of crystals in the direction (002). In addition, Si doping influenced the parameters of the lattice and crystallinity of the deposits, as shown in Table 1. The A-axis for the HS samples was shorter 
A

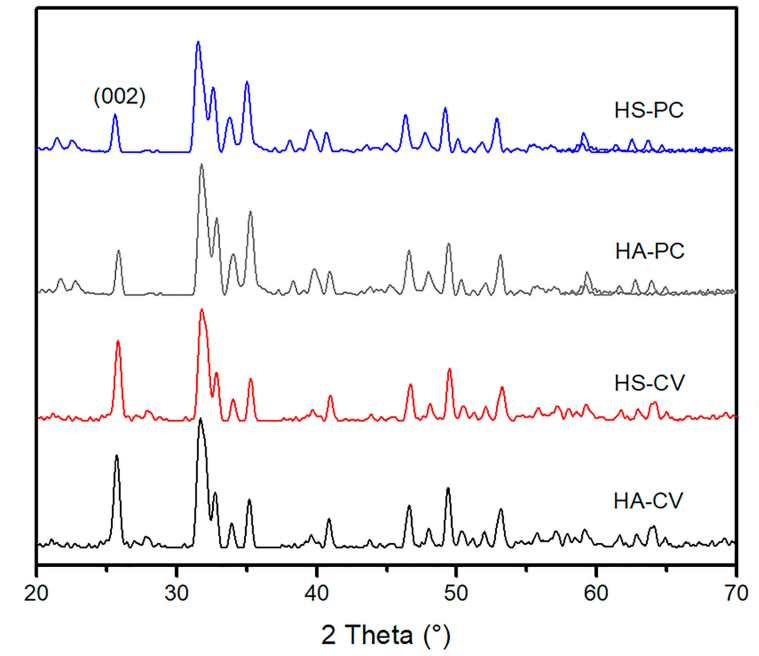

C

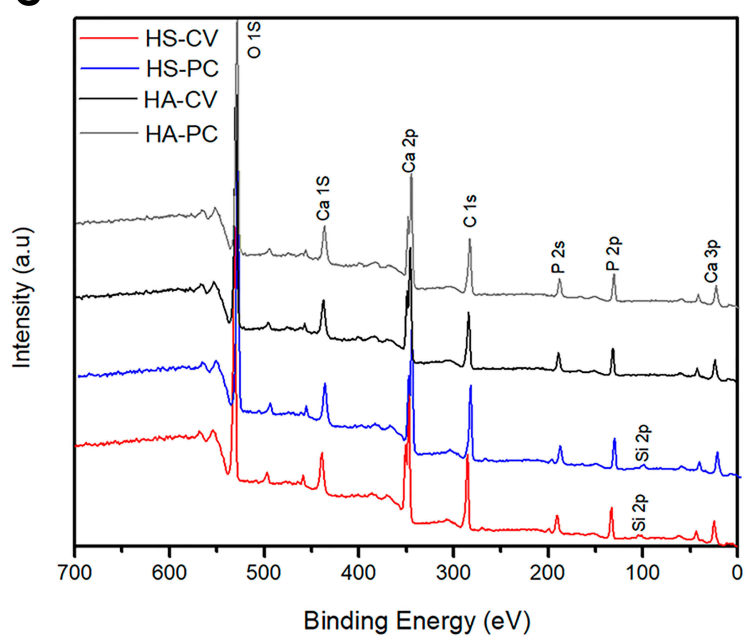

E

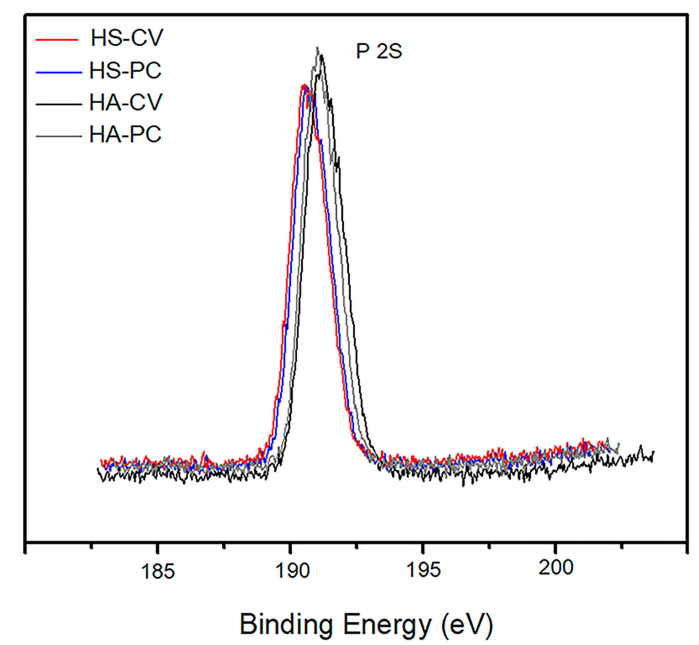

B

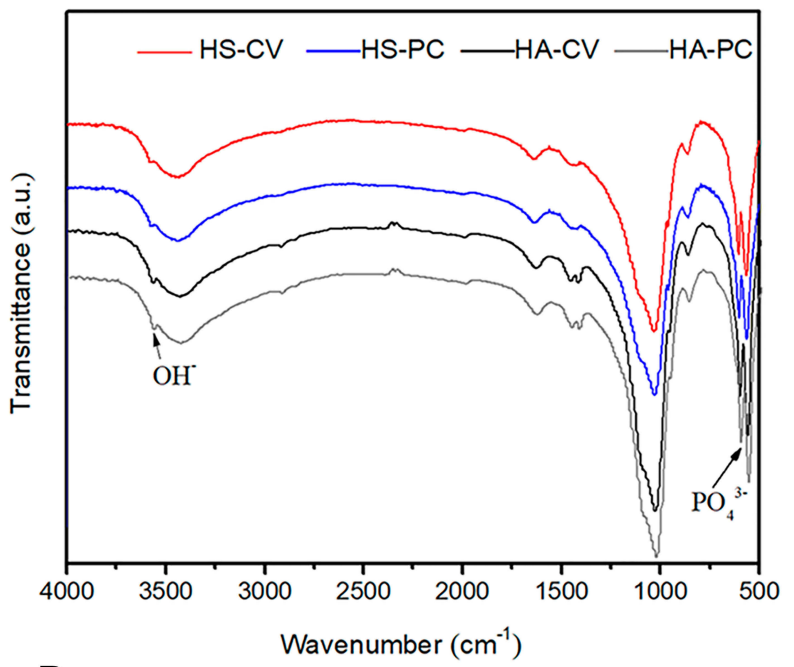

D

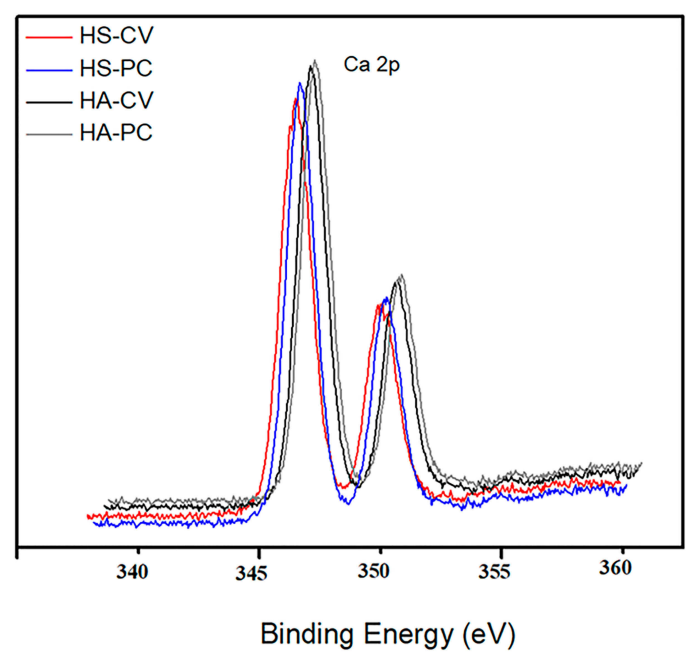

$\mathbf{F}$

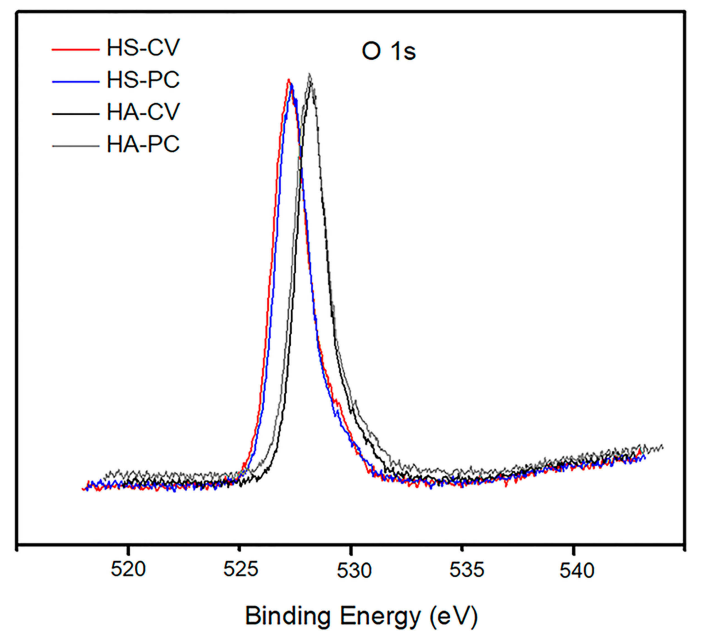

Figure 2 (A) XRD patterns, (B) FT-IR spectra, and (C-F) XPS spectra of the surface-coated Ti disks.

than that for the HA samples, and the C-axis for the HS samples was longer than that for the HA samples. The crystallinity of the HS samples was lower than that of the
HA samples. Moreover, the ED mode influenced the crystallinity of the deposits, where the CV samples had higher crystallinity than the PC samples. 
Table I Lattice Constant and Crystallinity of Four Types of Coatings on Ti Disks Prepared by ED Treatment Using the PC and CV Modes

\begin{tabular}{|l|l|l|l|l|}
\hline & HA-CV & HA-PC & HS-CV & HS-PC \\
\hline A $(\AA)$ & 9.459 & 9.458 & 9.432 & 9.443 \\
C $(\AA)$ & 6.887 & 6.890 & 6.900 & 6.928 \\
Crystallinity (\%) & 71.1 & 59.3 & 64.1 & 52.0 \\
\hline
\end{tabular}

Abbreviations: $\mathrm{Ti}$, titanium; $\mathrm{ED}$, electrochemical deposition; $\mathrm{PC}$, pulsed current; $\mathrm{CV}$, cyclic voltammetry; HA, hydroxyapatite; HS, silicon-doped hydroxyapatite.

Figure 2B shows the FT-IR spectra of surface deposits on the Ti disks prepared using the two ED modes. The characteristic peaks of $\mathrm{PO}_{4}{ }^{3-}$ and $\mathrm{OH}^{-}$were observed in all four samples. Compared with the HA samples, the HS samples with Si doping reflected a slight decrease in the densities of the peaks of $\mathrm{PO}_{4}{ }^{3-}$ and $\mathrm{OH}^{-}$. However, no prominent $\mathrm{Si}-\mathrm{O}$ characteristic peak was found in either HS sample, possible because of the relatively low Si content in the coatings. The XPS spectra are shown in Figure $2 \mathrm{C}-\mathrm{F}$. The characteristic peaks of $\mathrm{Ca}_{2 \mathrm{~s}}, \mathrm{Ca}_{2 \mathrm{p}}, \mathrm{Ca}_{3 \mathrm{p}}, \mathrm{P}_{2 \mathrm{~s}}, \mathrm{P}_{2 \mathrm{p}}$, and $\mathrm{O}_{1 \mathrm{~s}}$ were clear in the four samples. In both HS samples, the envelopes of peaks of $\mathrm{Si} 2 \mathrm{p}$ were clearly observed around $100 \mathrm{eV}$. Compared with the HA samples, the HS samples exhibited a slight left-shift in the peaks of $\mathrm{Ca}, \mathrm{P}$, and $\mathrm{O}$.

Figure 3A shows the surface wettability of the four surface-coated Ti disks. It is clear that all surfaces were hydrophilic, as confirmed by the small water contact angles. As shown in Table 2, the HS samples had smaller contact angles than the HA samples, and the PC samples had slightly smaller contact angles than the CV samples. Figure 3B shows the AFM analysis for the four surfacecoated Ti disks. Although all surfaces had nanoscale topographies, the PC samples had more surface protrusions and, thus, higher surface roughness than the CV samples. However, the Si doping had no significant influence on the surface roughness of the coating. The zeta potentials of the four surfaces are also summarized in Table 2. All four samples were negatively charged. The HS samples had higher absolute values than the HA samples, and the PC samples had slightly lower absolute values than the $\mathrm{CV}$ samples.

\section{Apatite Formation}

Figure $3 \mathrm{C}$ shows surface morphologies of the four surfacecoated Ti disks after immersion in SBF for $12 \mathrm{~h}$ and 24 h. After $12 \mathrm{~h}$ of immersion, except HA-CV, the other three surfaces had bone-like apatite deposited on them. Compared with the HA samples, the HS and PC samples were favorable for promoting apatite deposition. With the increase in soaking time to $24 \mathrm{~h}$, the surfaces of all samples were covered by apatite deposits thicker than before.

\section{BSA Adsorption}

Figure 4A shows BSA adsorption on the four surfacecoated Ti disks. It is clear that both surface morphology and Si doping affected the adsorption of BSA on the surface of the coating. The HS samples had higher BSA adsorption capacity than the HA samples, and the PC samples exhibited higher BSA adsorption capacity than the $\mathrm{CV}$ samples.

\section{Behavior of MC3T3-EI Cells Cell Growth, Viability, and Spread}

Figure 4B shows CLSM observations for the growth of the cells cultured on the four surface-coated Ti disks. With increased culturing time, live cells on the surface of each sample increased prominently and exhibited a normal cell morphology. On day five, the live cells covered the entire surface of each sample. Moreover, nearly no dead cell was found on the surface of any sample, demonstrating the good biocompatibility of the samples.

Figure $4 \mathrm{C}$ presents the CCK-8 analysis of cells cultured on the four surface-coated Ti disks. It is clear that the cells maintained good viability in growth on the surface of each sample. On day one, no significant difference in cell viability was found among the four groups of samples. On day three, the HS samples exhibited higher cell viability than the HA samples. On day five, the PC samples exhibited slightly higher cell viability than the $\mathrm{CV}$ samples. Of the four groups, HS-PC had the best effect on cell viability.

Figure 4D shows the spreading morphology of cells cultured on the four surface-coated Ti disks for one day. Compared with the CV samples, the PC samples allowed the cells greater cytoplasmic expansion and filamentous pseudopodia extension, and a round or elliptical nucleus, thus exhibiting a better cell spreading state. Figure $4 \mathrm{E}$ shows a quantitative analysis of the area of spreading of the cells on the surface. It is clear that PC samples with nanosheet coating led to a larger cell spreading area than $\mathrm{CV}$ samples with nanorod coating. However, for either nanosheet or nanorod coating, there was no significant difference in the cell spreading area between the HA and the HS samples. This indicates that $\mathrm{Si}$ doping had no prominent influence on the spreading of the MC3TE-E1 cells. 


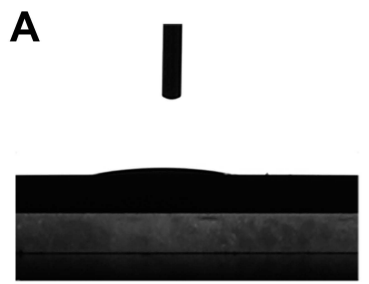

HA-CV

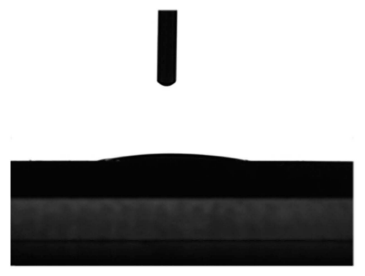

HA-PC

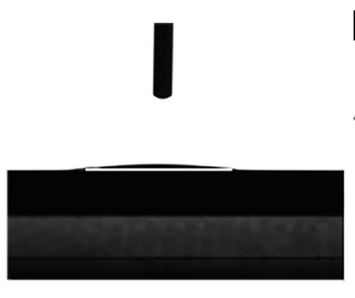

HS-CV

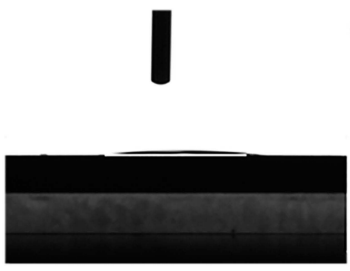

HS-PC
B

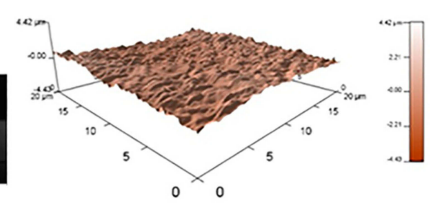

HA-CV

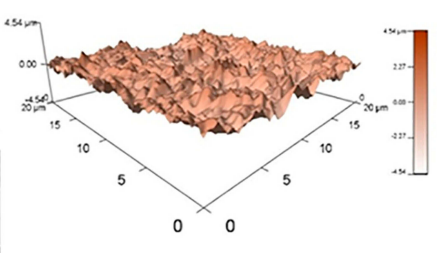

HA-PC

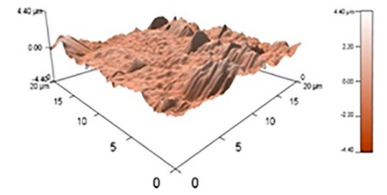

HS-CV

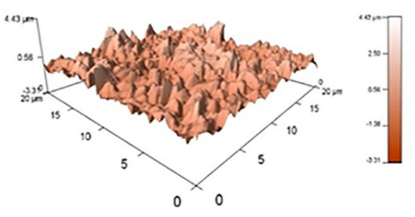

HS-PC

C
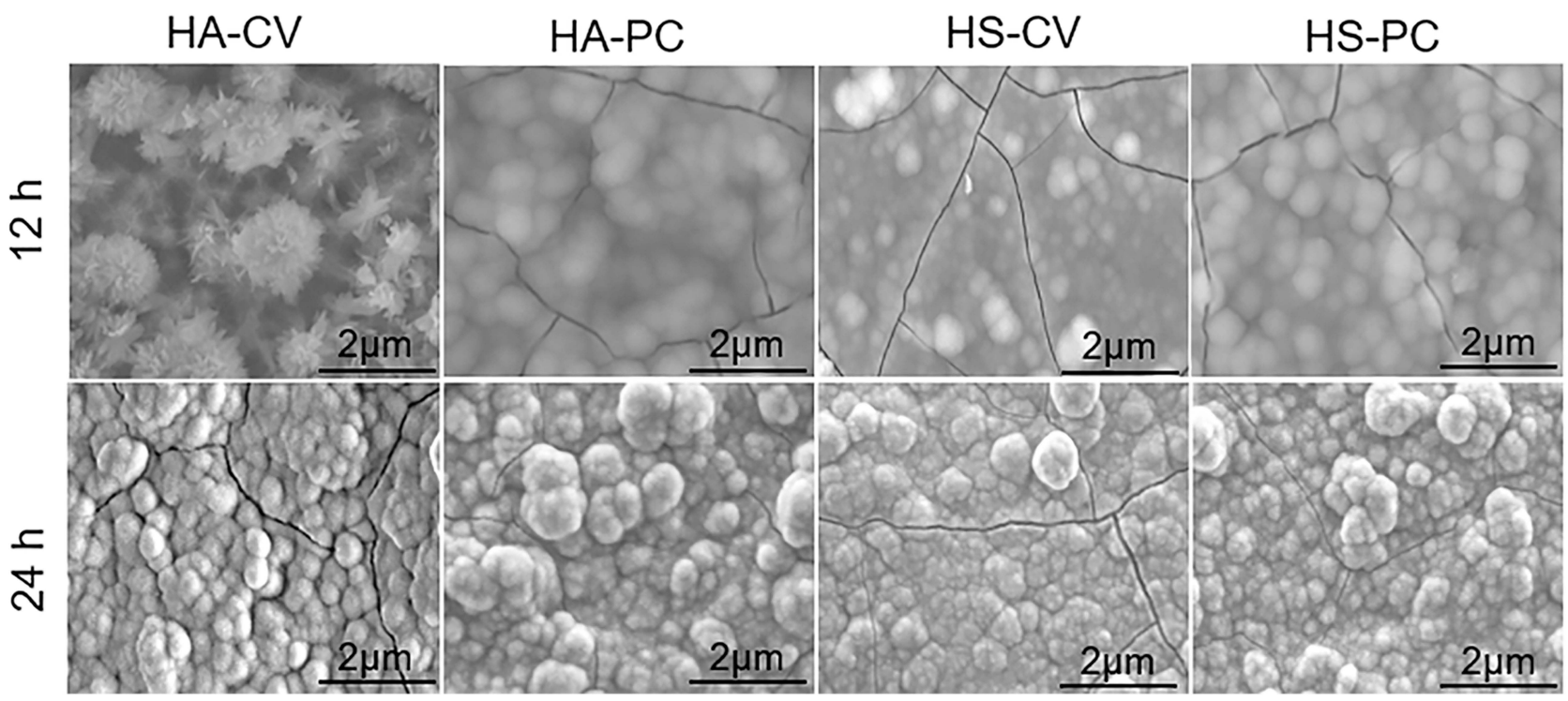

Figure 3 (A) Surface wettability tests. (B) AFM images of the surface-coated Ti disks. (C)

(C) SEM images of the surface-coated Ti disks after immersion in SBF for $12 \mathrm{~h}$ and $24 \mathrm{~h}$.

Osteogenesis-Related Gene Expressions of the Cells Figure 5 shows the results of the PCR analysis of the expressions of five osteogenesis-related genes (ALP, Col-I, OSX, OPN, OCN) in cells cultured on the four surface-coated Ti disks for seven and 14 days. For ALP and OCN, only HS-PC promoted significantly higher gene expression than the control on day 14. For Col-I and OSX, no experimental group up-regulated its gene expressions on day seven, but both HS groups had far higher gene expression than the control. No significant difference was observed in the expressions of ColI and OSX genes between the HS-PC and the HS-CV groups.
For OPN, all experimental groups up-regulated gene expression on days seven and 14 compared with the control. In particular, both PC samples with nanosheet coating better promoted OPN gene expression than both $\mathrm{CV}$ samples with nanorod coating on day 14.

The ALP activity of MC3TE-E1 cells cultured on each surface-coated Ti disk was also tested, as shown in Figure S3. On day seven, there was no significant difference in ALP activity between the four experimental groups and the control group. However, on day 14, all the four experimental groups significantly up-regulated ALP activity compared with the 
Table 2 Water Contact Angles, Surface Roughness Values, and Zeta Potentials of the Four Surface-Coated Ti Disks

\begin{tabular}{|l|l|l|l|l|}
\hline & HA-CV & HS-CV & HA-PC & HS-PC \\
\hline Contact angle ( $\left.{ }^{\circ}\right)$ & $11.5 \pm 0.9$ & $8.1 \pm 0.5$ & $10.3 \pm 0.3$ & $7.3 \pm 0.2$ \\
Surface roughness & 341.2 & 384.6 & 477.5 & 486.6 \\
$(\mathrm{~nm})$ & \pm 89.2 & \pm 112.6 & \pm 66.8 & \pm 99.0 \\
Zeta potential (eV) & $-20.4 \pm 0.5$ & $-27.1 \pm 0.8$ & -18.25 & $-24.5 \pm 1.0$ \\
& & & \pm 1.1 & \\
\hline
\end{tabular}

Abbreviations: $\mathrm{Ti}$, titanium; $\mathrm{HA}$, hydroxyapatite; $\mathrm{HS}$, silicon-doped hydroxyapatite; CV, cyclic voltammetry; PC, pulsed current.

control. In line with the PCR analysis, HS-PC had the best effect.

\section{Behavior of HUVECs}

\section{Cell Growth, Viability, and Migration}

Figure 6A shows CLSM observations of the growth of HUVECs cultured with leach liquors of the surface-coated Ti disks immersed in the serum-free DMEM for seven days. At each time point, the live cells presented a normal growth morphology on each sample, and nearly no dead cell was found. With the prolonged culturing time, more living cells were observed on the sample surface, especially on both nanosheet coatings. Figure $6 \mathrm{~B}$ shows the CCK-8 analysis of the viability of cells cultured with the leach liquors. Cell viability on each sample increased with the culturing time. On day five, all experimental groups exhibited higher cell viability than the control, in accordance with the CLSM observations.

Figure 6C shows the assay of wound healing for the migration capability of HUVECs cultured with leach liquors of the surface-coated Ti disks. Light microscope images showed that only tiny cells appeared on the control group in the area of the wound. However, in each experimental group, a large number of cells migrated into the area of the wound after it had been scratched for $12 \mathrm{~h}$ and $24 \mathrm{~h}$. Figure 6D shows the quantitative evaluation of cell migration. A larger healing area implied better cell migration which was in the order HS-PC $>$ HS-CV $>$ HA-PC $>$ $\mathrm{HA}-\mathrm{CV}$. At $24 \mathrm{~h}$, the rate of healing of the wound in the HS-PC group was nearly $60 \%$, indicating the primary role of $\mathrm{Si}$ ion release in promoting the migration of HUVECs.

\section{Angiogenesis in vitro and NO Staining}

Figure 7A shows light microscope images of HUVECs cultured on ECMatrix ${ }^{\mathrm{TM}}$ for $8 \mathrm{~h}$ in the presence of leach liquors of the surface-coated Ti disks. No prominent tubular structure was observed in the control group, where only a small number of nodes and junctions were found.
Compared with the HA groups, greater tube formation was observed in the HS groups. Figure 7B shows a quantitative analysis of the numbers of nodes and junctions, and the length of the branch and total length. Significantly, all four experimental groups had more nodes and junctions than the control group, indicating good tendency toward tube formation. Compared with the HA groups, the HS groups had considerably longer tubes, and no significant difference was observed between HS-PC and HS-CV. These results mean that Si ion release, and not the coating morphology, promoted the angiogenesis of HUVECs in vitro.

Figure 7C and D show the NO staining and quantitative evaluation of HUVECs cultured with leach liquors of the surface-coated Ti disks for five days. The color of the media was darker in the HS groups than the HA groups. The quantitative analysis showed the same results. Higher NO content was found in the HS groups than the HA groups. Without Si doping, HA-PC exhibited 20\% higher NO content than HA-CV. However, with Si doping, there was no significant difference in NO content between HS$\mathrm{PC}$ and HS-CV. The results indicate that compared with the coating morphology, $\mathrm{Si}$ doping stimulated more NO content in the HUVECs.

\section{Angiogenesis-Related Gene Expressions}

Figure 8 shows the PCR analysis of angiogenesis-related gene expressions (VEGF, bFGF, eNOS and Ang-1) of the HUVECs after being cultured with leach liquors of the surface-coated Ti disks for seven and 14 days. For VEGF, the HS groups, but not the HA groups, up-regulated gene expression on days seven and 14 compared with the control group. HS-PC had a better effect than HS-CV. For bFGF, no any experimental group up-regulated gene expression on day seven. But on day 14, both HS groups stimulated higher gene expressions than the control group. HS-PC had a better effect than HS-CV. For eNOS, all four experimental groups up-regulated gene expression on day 14, and HS-PC had the best effect. For Ang-1, although HS-PC always stimulated higher gene expression than the other three experimental groups, no any experimental group had an upregulating effect compared with the control group.

\section{Discussion}

The ED method has the advantage being able to fabricate a homogeneous bioactive coating on the surface of a biomaterial such that various working modes, including the constant potential (CP), PC, and CV, can be used. Thus 
A

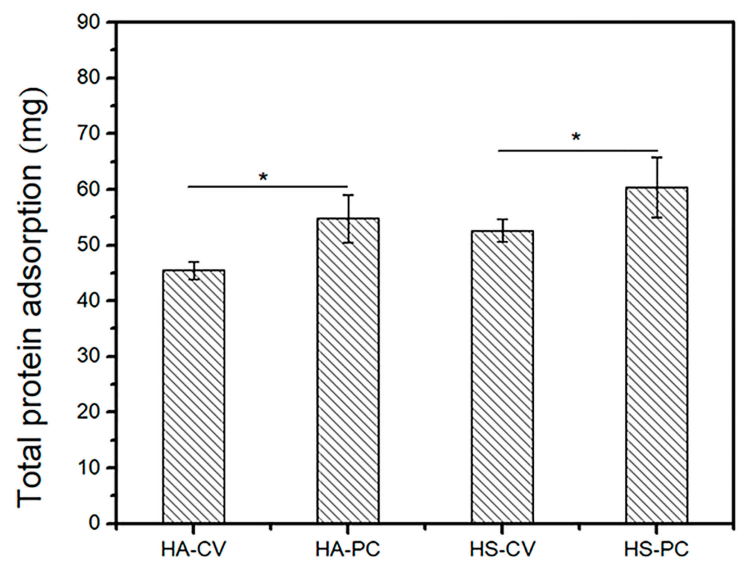

C

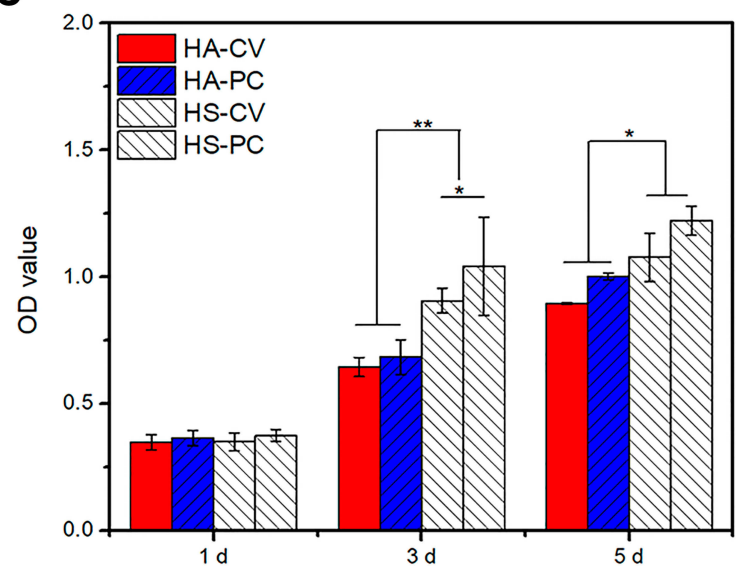

E

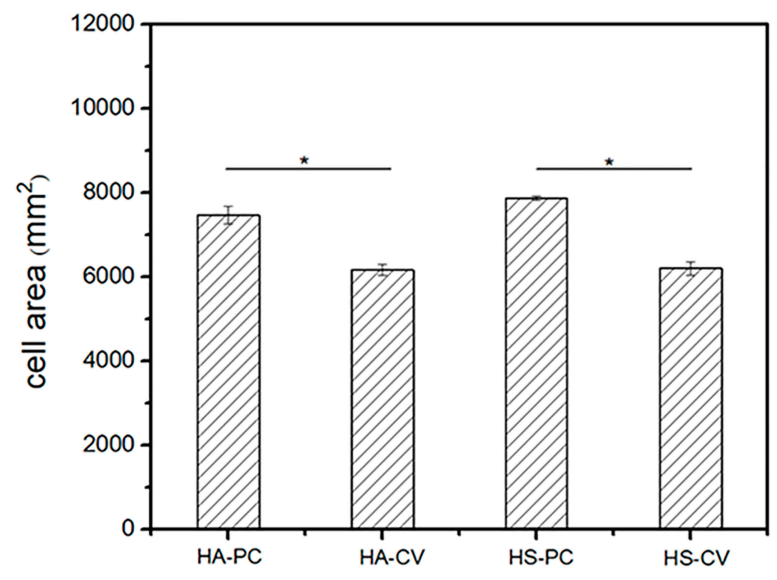

B

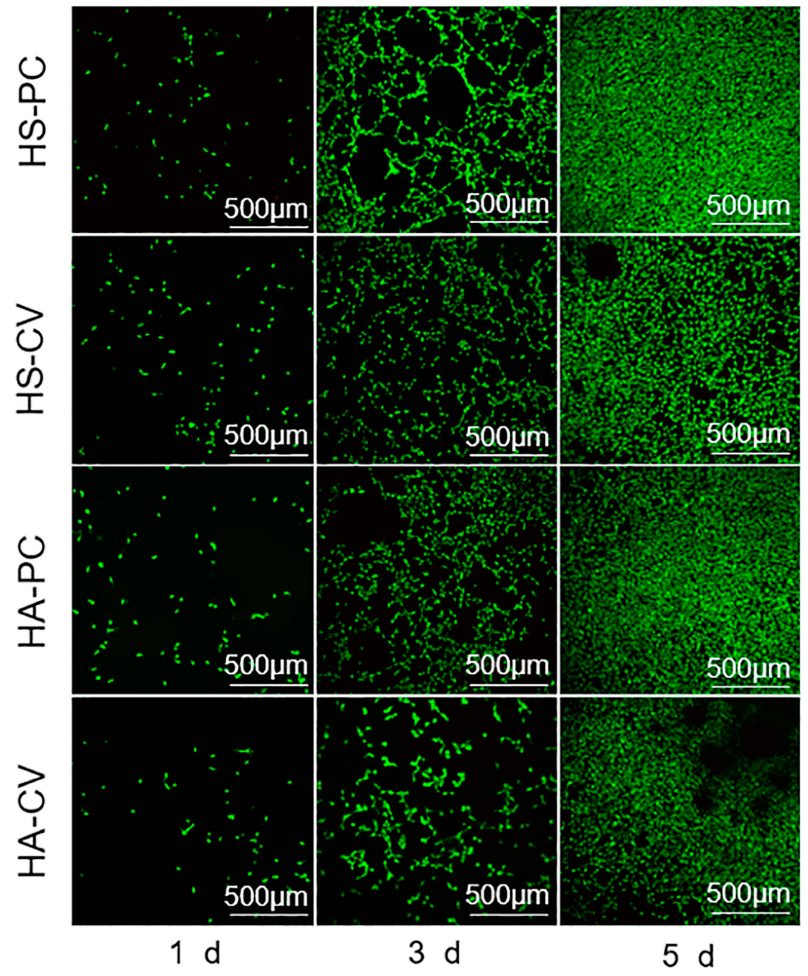

D

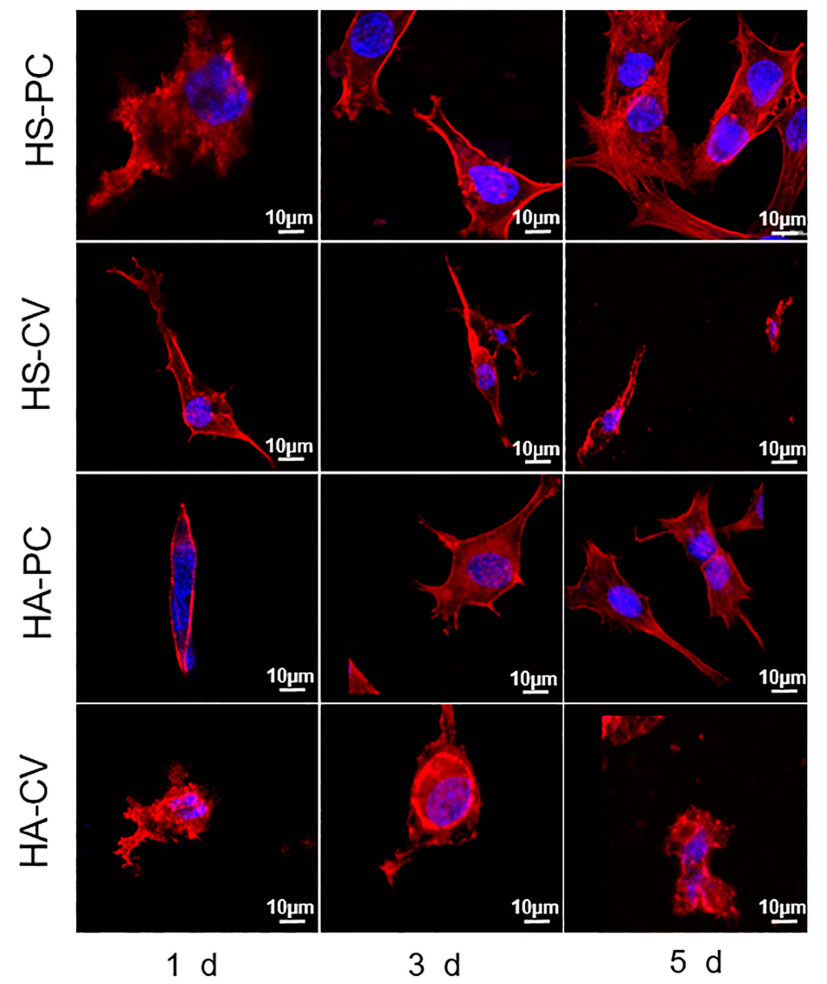

Figure 4 (A) Protein adsorption on the surface-coated Ti disks. (B) CLSM observation on MC3T3-EI cells cultured on the surface-coated Ti disks for one, three and five days. (C) Viabilities of MC3T3-EI cells cultured on the surface-coated Ti disks for one, three and five days. (D) Cell cytoskeleton staining, and (E) Quantitative evaluation of MC3T3-EI cells cultured on the surface-coated Ti disks for one day $\left({ }^{*} p<0.05,{ }^{* *} p<0.01, n=3\right)$. 

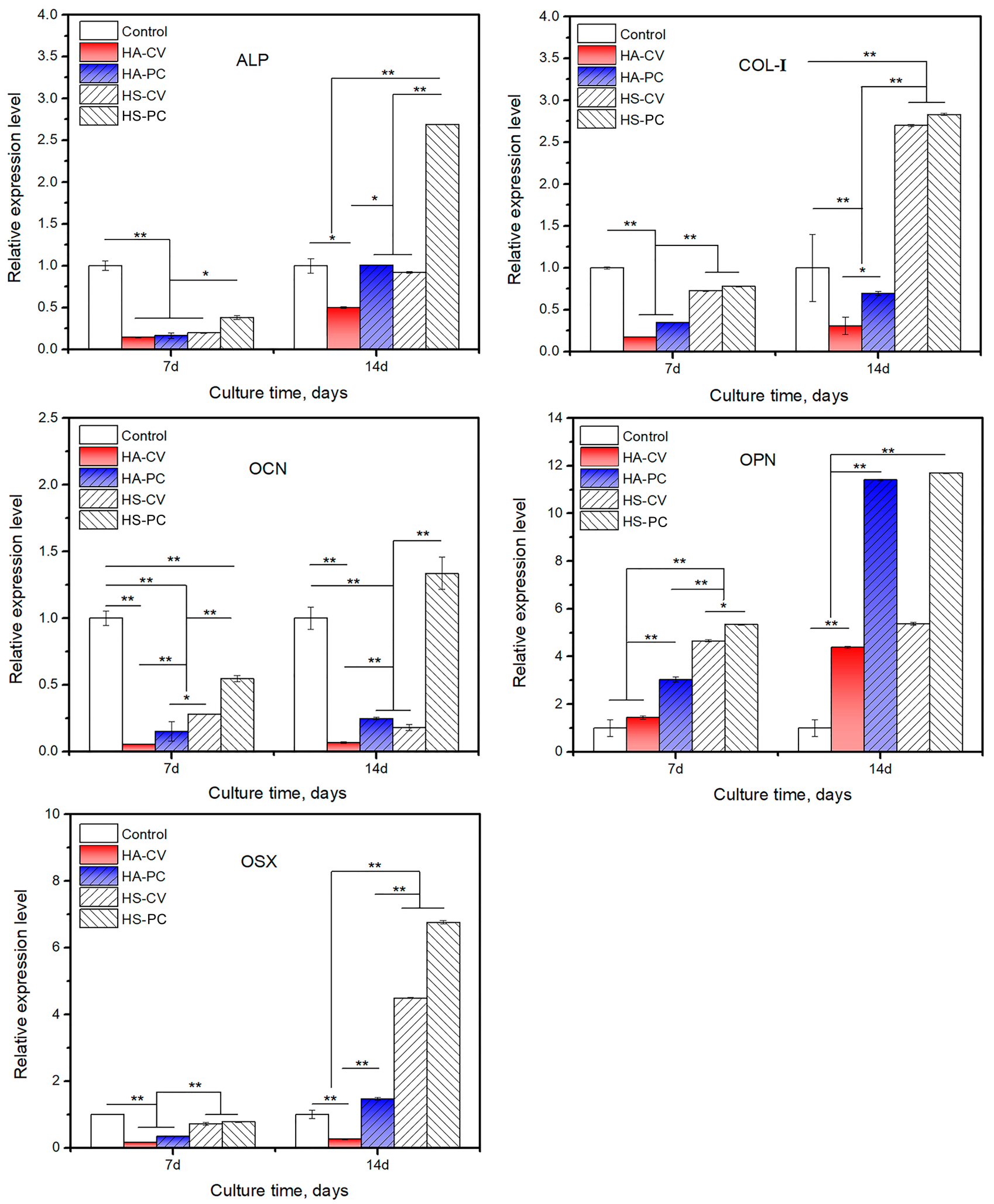

Figure 5 PCR analysis of osteogenic gene expressions of the MC3T3-EI cells cultured on the surface-coated Ti disks for 7 and I4 days $\left({ }^{*} p<0.05, * * p<0.01, n=3\right)$.

far, a considerable amount of research has focused on the pure HA but not the HS coating prepared by using the ED method. In general, compared with other methods of preparation, the $\mathrm{Si}$ content in the ED coating is low. Even at a deposition temperature of $85^{\circ} \mathrm{C}$, it is difficult to provide enough energy for $\mathrm{Si}$ doping in HA because it has a larger ionic radius than 


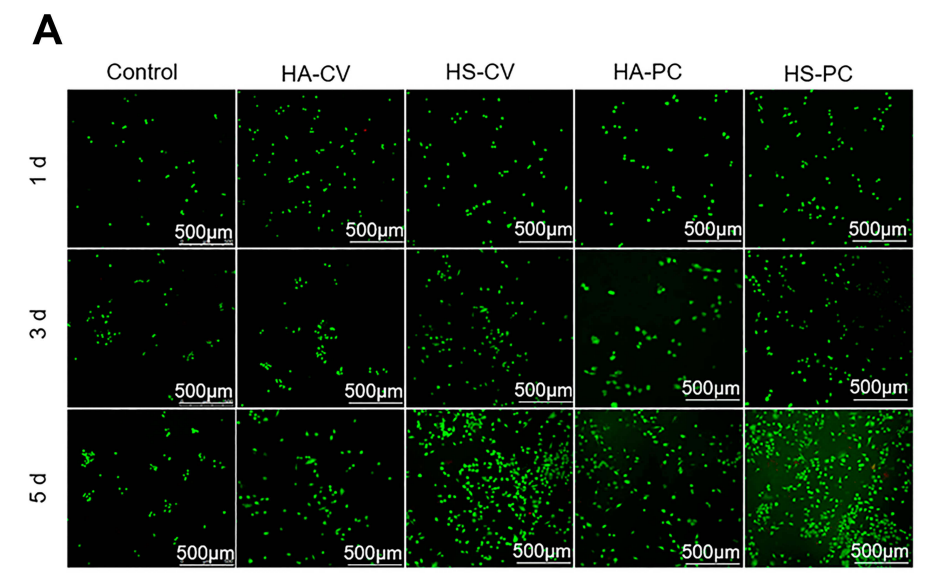

B
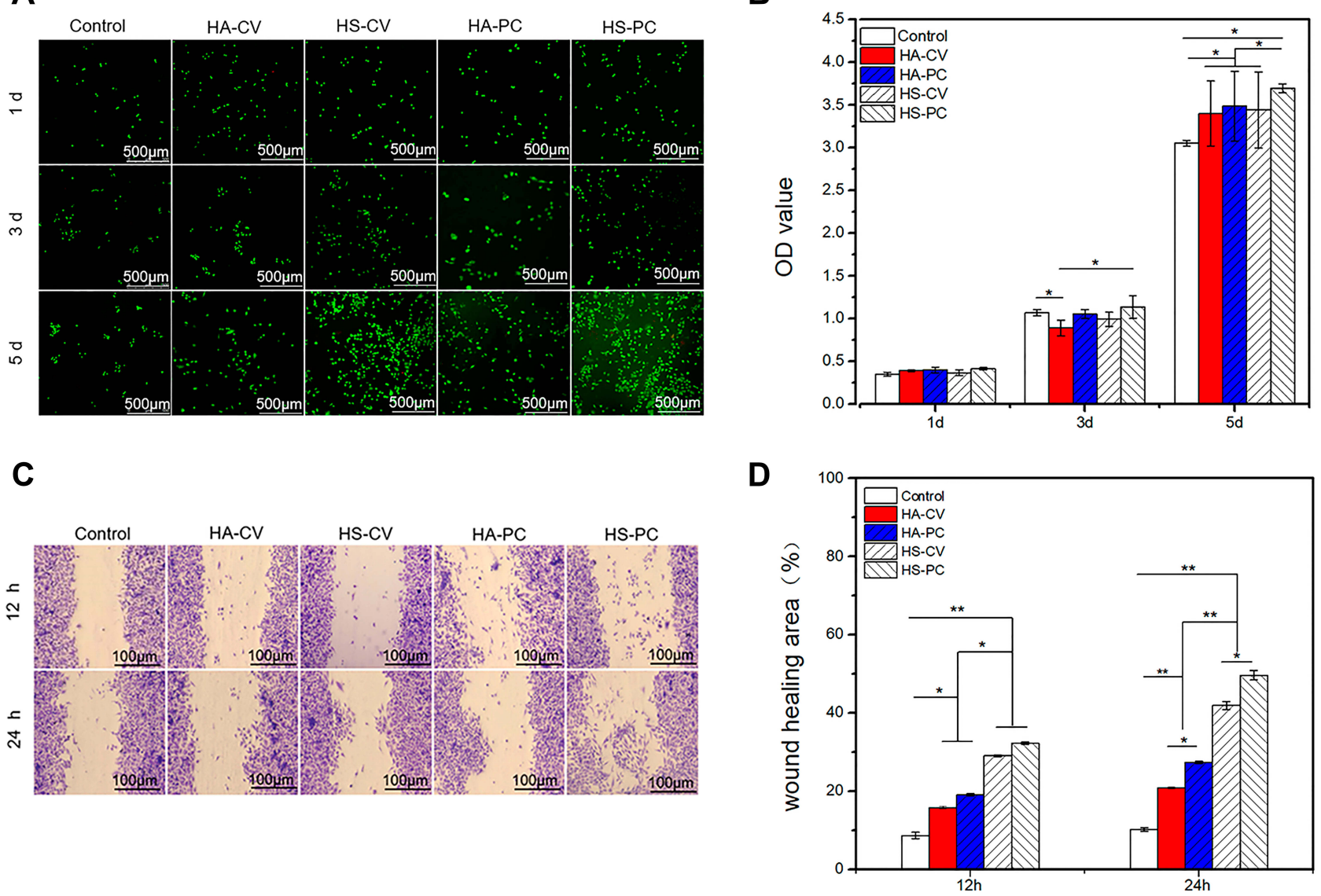

Figure 6 (A) CLSM observation of HUVECs cultured with leach liquors of the surface-coated Ti disks for one, three and five days. (B) Viabilities of HUVECs cultured with leach liquors of the surface-coated Ti disks for one, three and five days. (C) Wound healing assay, and (D) quantitative evaluation of the migration capability of HUVECs after being cultured with leach liquors of the surface-coated Ti disks for $12 \mathrm{~h}$ and $24 \mathrm{~h}\left({ }^{*} p<0.05, * * p<0.0 \mathrm{I}, \mathrm{n}=3\right)$.

P. Moreover, negatively charged Si ions are repelled from the cathode filled with electrons, resulting in a lower concentration of Si ions near the Ti substrate and, thus, lower Si content in the final HA coating. Li et al used the CP method to fabricate a tree-like HS coating with saturated Si content of 0.55 wt. $\%{ }^{24}$ However, in this study, the HS coating with a relatively high $\mathrm{Si}$ content was prepared by the ED method using the $\mathrm{PC}$ or the $\mathrm{CV}$ mode, and the coating topography was regulated by adjusting the processing parameters. The Si content in the coating can be above $1.0 \mathrm{wt} . \%$ (Figure S2). Zhang et al fabricated an Si-HA coating with 0.39 wt.\% Si content on a porous Ti scaffold by a biomimetic process, and found that this coating had significantly higher bioactivity than the pure HA coating. ${ }^{25}$ Hing et al reported that 0.8 wt. $\%$ of Si content in the Si-HA ceramic scaffold or coating may exhibit higher osteogenic activity. ${ }^{26}$ Hence, coatings with 0.8 wt.\% Si content were investigated.

Our previous study confirmed that in the PC mode, the morphology of the ED deposits can transform from a plate- like to a nanorod-like structure when the current density changes from -5 to $-10 \mathrm{~mA} / \mathrm{cm}^{2} .{ }^{20}$ In this study, in the PC mode, the current density was $-5 \mathrm{~mA} / \mathrm{cm}^{2}$, and the nanosheet topography of the coating with lower crystallinity was acquired. However, in the CV mode, nanorod coatings with higher crystallinity were obtained (Figure 1A and Table 1). Jeong et al investigated the influence of the deposition cycle and voltage on the morphology of the $\mathrm{Si}$ $\mathrm{Ca} / \mathrm{P}$ coating, and found that with prolonged deposition time and increased voltage, the topography of the coating gradually transformed from a needle-like structure with lower crystallinity to a plate-like one with slightly higher crystallinity. ${ }^{27}$ Compared with this (17 min deposition time and $36.5{ }^{\circ} \mathrm{C}$ deposition temperature), a longer deposition time $(20 \mathrm{~min})$ and higher deposition temperature $\left(85^{\circ} \mathrm{C}\right)$ were used here, because of which nanorod coatings with higher crystallinity formed on the surface of Ti. Note also that in either the PC or the CV mode, the coating topography was barely influenced by Si doping, but the crystallinity 
A

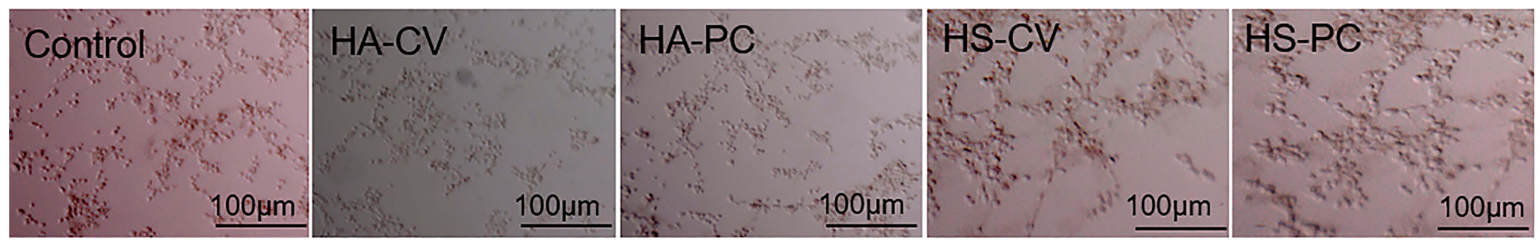

B
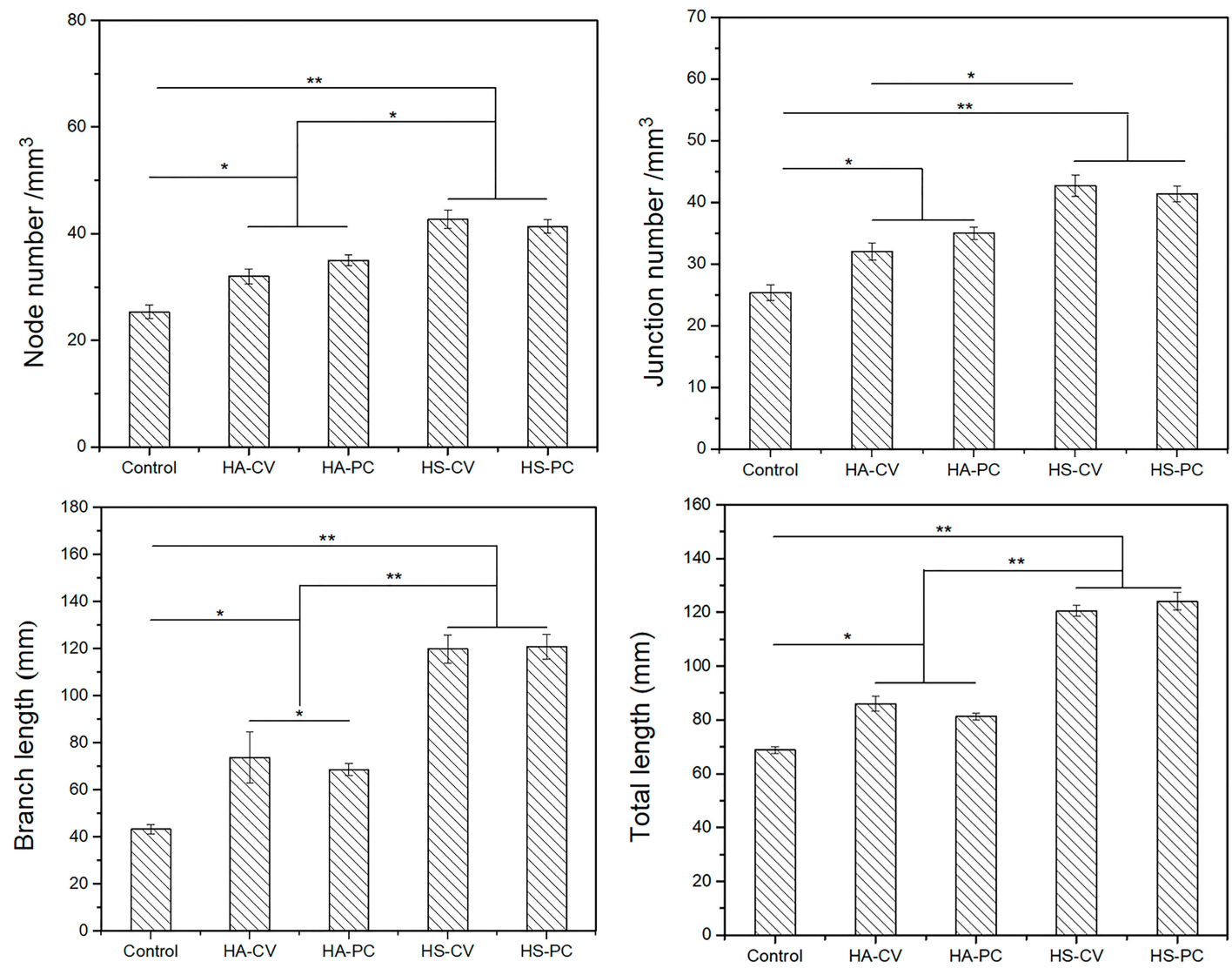

C

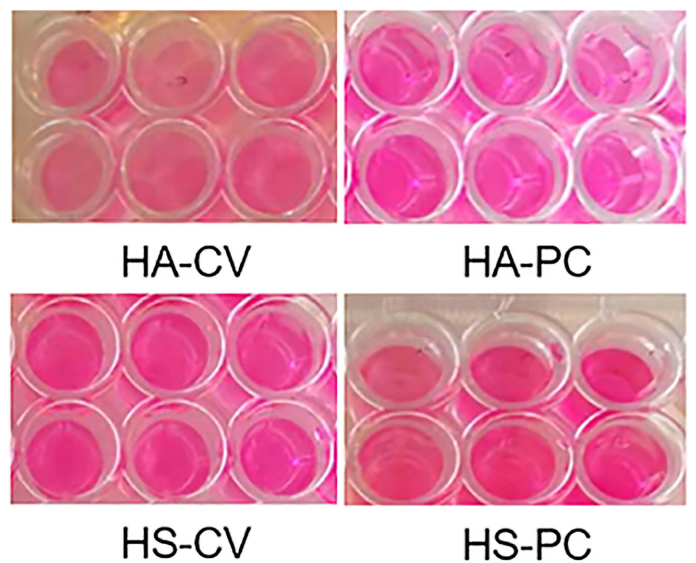

D

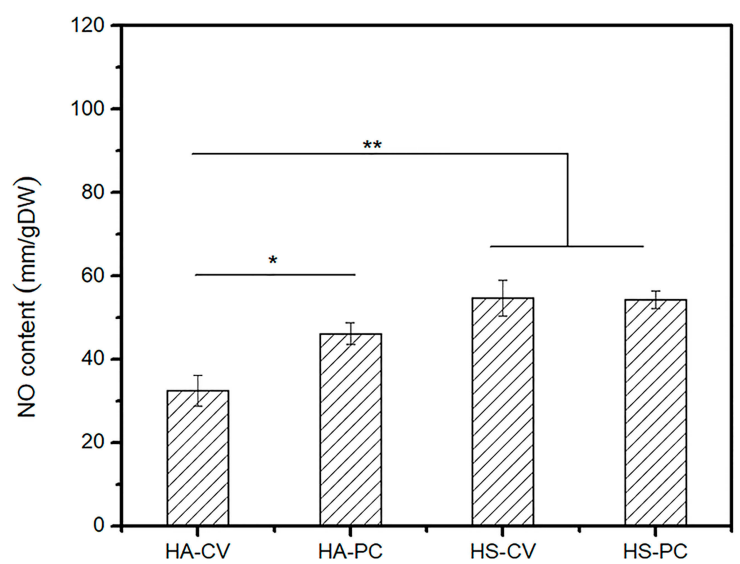

Figure 7 (A) Light microscope photos, and (B) quantitative evaluation (node, junction, branch, and total length) of HUVECs after being cultured on an ECMatrix ${ }^{\mathrm{TM}}$ for 8 $h$ in the presence of leach liquors of the surface-coated Ti disks. (C) NO staining, and (D) quantitative evaluation of HUVECs after being cultured with leach liquors of the surface-coated Ti disks for five days $\left({ }^{*} p<0.05\right.$, ** $p<0.0$ I, $\left.n=3\right)$. 

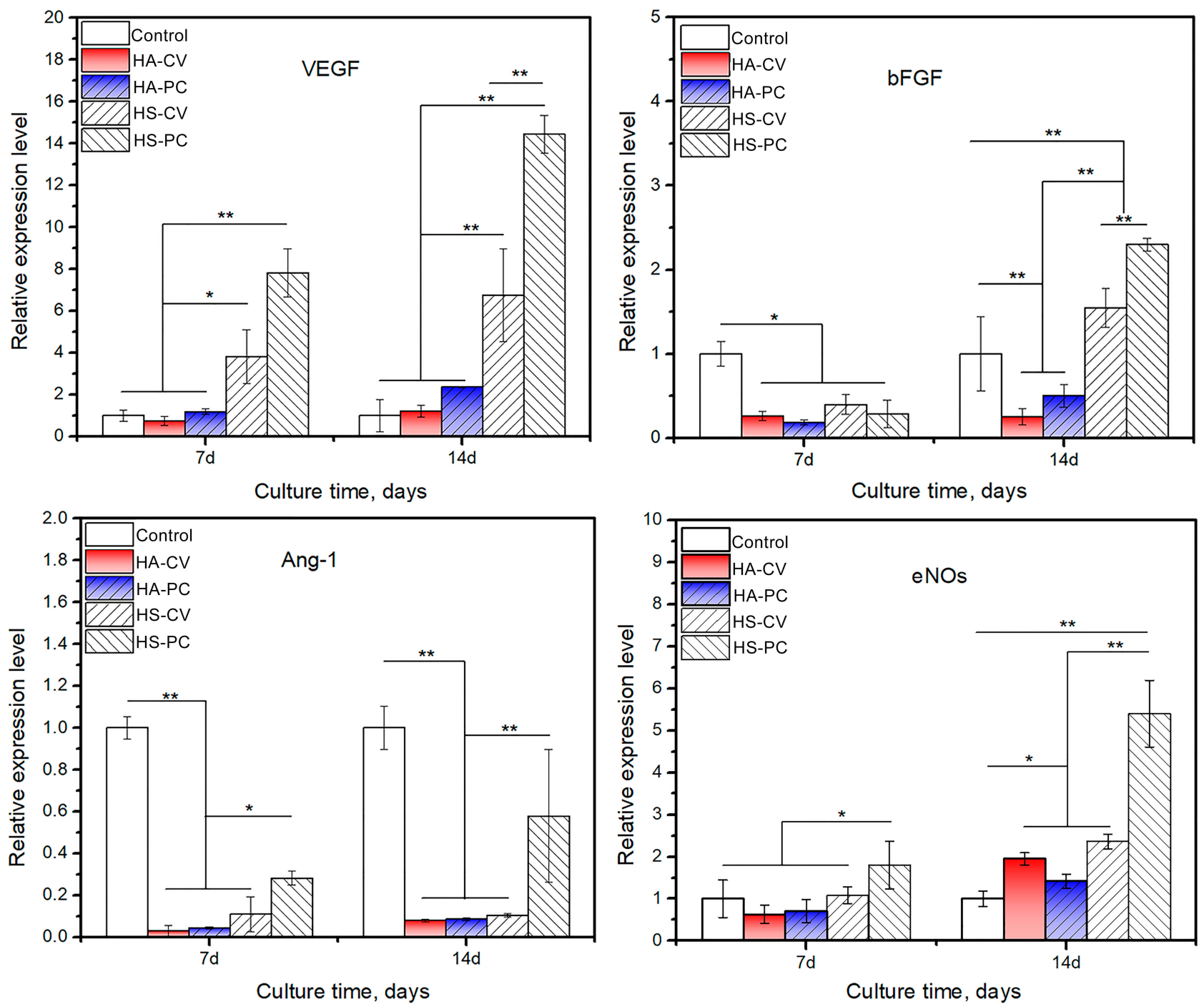

Figure 8 PCR analysis of angiogenesis-related gene expressions in HUVECs after being cultured with leach liquors of the surface-coated Ti disks for 7 and I4 days $(* p<0.05$, $* * p<0.01, n=3)$.

and lattice constant changed slightly (Figure 1A and Table 1). In the coating for HS-CV, incorporating Si could have inhibited the growth of the HA crystals, especially the preferred direction of growth (002). The longitudinal growth of the HA crystals slowed down, leading to incomplete separation of the deposited rod-like crystals on the surface of Ti with tendency to assume a flake-like shape, which is in accordance with previous reports. ${ }^{24,28}$ This was also verified by the XRD pattern (Figure 2A), where a decreased intensity of the (002) peak in the two HS samples was observed. This inhibitory effect gave rise to changes in the lattice constant of the crystals, ie, a slight decrease in the $\mathrm{A}$-axis and an increase in the $\mathrm{C}$-axis (Table 2). According to the FT-IR spectra (Figure 2B), smaller peaks of $\mathrm{OH}^{-}$and $\mathrm{PO}_{4}{ }^{3-}$ occurred in the HS samples than in the HA samples, possibly due to a difference in valence states between $\mathrm{SiO}_{4}{ }^{4-}$ and $\mathrm{PO}_{4}{ }^{3-}$. The HS coating with Si doping could have lost some $\mathrm{OH}^{-}$ ions to satisfy the requirement of charge balance, ${ }^{29}$ in accordance with the charge balance theoretical model proposed by Gibson et al. ${ }^{30}$ The Si-O peaks were not observed in the FT-IR spectra, possible because of the lower $\mathrm{Si}$ content in the coating and the $\mathrm{CO}_{3}{ }^{2-}$ generated during the preparation of the coating. During the ED process, contact with air could have introduced $\mathrm{CO}_{3}{ }^{2-}$ to the coating, which in turn influenced the detection of peaks of $\mathrm{Si}-\mathrm{O} .{ }^{30,31}$ The $\mathrm{Si}$ doping was verified by XPS spectra (Figure 2C and D), where the peaks of $\mathrm{Si} 2 \mathrm{p}$ were prominent, and there was a slight left-shift in the peaks of $\mathrm{Ca}, \mathrm{P}$, and $\mathrm{O}$ in the $\mathrm{HS}$ samples compared with the HA samples. 
The surface characteristics of a biomaterial play an important role in its biological performance. After being implanted in the body, the biomaterial first comes into contact with the blood and body fluids, which leads to the quick adsorption of proteins on the surface of the substrate. The adsorbed protein layer affects subsequent cell adhesion, proliferation and differentiation. ${ }^{32}$ Protein adsorption is a complex process that is affected by the $\mathrm{pH}$ and ionic composition of the solution as well as such surface characteristics of the material as roughness, specific surface area, and surface potential. ${ }^{33-36} \mathrm{Si}$ doping and changes in the morphology led to changes in surface characteristics of the ED coating (Table 2), and thus affected its protein adsorption capacity. All HA and HS samples had negatively charged surfaces. Therefore, they were repulsive to the negatively charged BSA in the PBS. A rough surface can provide more sites for protein adsorption and enhance protein adsorption capacity. ${ }^{34,37}$ Previous studies have shown that the presence of a small amount of $\mathrm{Si}$ in the solution forms a silicate network structure on the surface of coating, which causes the proteins to integrate in a certain way. ${ }^{38}$ Thus, the nanosheet HS-PC coating with higher surface roughness and Si doping exhibited the highest BSA adsorption capacity of the four samples (Figure 4A).

Apatite formation on the surface via SBF immersion is commonly used for characterizing the bioactivity of a biomaterial in vitro. The results here showed that all four coatings had good apatite-forming ability. After being soaked in SBF for $12 \mathrm{~h}$, only the nanorod HA-CV coating without Si doping had tiny deposits on its surface. The other three coatings had an entire layer of bone-like apatite formed on their surfaces. After $24 \mathrm{~h}$ of immersion, the surfaces of all four coatings were covered with apatite. In case of the ED-induced coating, the nanosheet coating had lower crystallinity than the nanorod coating, and the Sidoped coating had lower crystallinity than the pure HA coating (Table 2). As a result, HA-CV exhibited slower dissolution of $\mathrm{Ca}^{2+}$ and $\mathrm{PO}_{4}{ }^{3-}$ than the other three coatings (Figure 1C). Chen et al found that the rapid dissolution of $\mathrm{Ca}^{2+}$ in an aqueous solution can accelerate the deposition of bone-like apatite on the surface of $\mathrm{Ti}$ and improve the osteogenic ability of the implant. ${ }^{39}$ Previous studies have shown that certain surface micro/nano structures can promote the growth of bone-like apatite on the surface of $\mathrm{Ti}$, and enhance its osseointegration ability. ${ }^{40,41}$ Kokubo et al reported that the addition of $\mathrm{Si}$ can increase the formation of bone-like apatite on the surface of the substrate. ${ }^{2}$ Thus, the relatively high dissolutions of the $\mathrm{Ca}, \mathrm{P}$, and $\mathrm{Si}$ ions, as well as the rough and hydrophilic surface led to rapid apatite deposition on the surface of the coating.

Previous studies have shown that nanotopographic modification of the Ti implant can enhance osteointegration ability. ${ }^{42,43}$ The MC3T3-E1 pre-osteoblasts were selected here as model to investigate the osteogenic activity of the surface-coated Ti disks. All four coatings allowed for the good growth, attachment, and proliferation of the cells, which had a normally flattened and wellspread morphology as well as good viability (Figure 4B and D). It is known that after seeding on the surface of a biomaterial, the cells undergo morphological changes to stabilize the cell-material interface. ${ }^{44}$ Moreover, it has been reported that the addition of $\mathrm{Si}$ can stimulate cell proliferation. ${ }^{45,46}$ Therefore, of the four coatings, HS-PC exhibited the best viability for the MC3T3-E1 cells (Figure 4C).

In the course of cell differentiation, a series of gene expressions were triggered in the cells under stimulation from the environment. The up-regulated expressions of the gene encodings of ALP, Col-I, OSX, OPN and OCN were key factors for inducing osteoblastic differentiation among the cells. ${ }^{47}$ In case of the ED-induced coating, both Si doping and the topography of the coating affected the osteogenic gene expressions in the MC3T3-E1 cells to some extent, and only the Si doping exhibited a stronger effect than the coating topography (Figure 5). On day 14, for the five tested genes, a significantly higher expression was found in the HS-PC group than the other groups. For Col-I and OSX, no significant difference in gene expression was found between HS-PC and HS-CV, indicating the primary role of Si doping. But for ALP, OPN and OCN, far higher gene expressions were found in HS-PC than HS$\mathrm{CV}$, demonstrating the synergistic effects of the Si doping and coating topography. The positive role of $\mathrm{Si}$ in stimulating osteogenic differentiation among the cells has been confirmed by previous studies on such silicates as Sicontaining bioglass ${ }^{48}$ and calcium silicate. ${ }^{49}$ Liu et al fabricated a highly crystalline Si-nHA coating on a Ti implant through atmosphere plasma spraying combined with hydrothermal treatment, and confirmed the good osteointegration of the implant using a diabetes model. This indicates synergistic promotion by the nanostructure and Si substitution in the HA coating. ${ }^{50}$

Angiogenesis is a complex multi-step process that plays a vital role in repairing highly vascularized bone tissue. $^{51,52}$ The continuity of the endothelial cells (ECs) 
is crucial to maintaining the function of the vascular wall. The migration of ECs is essential to the recovery of this continuity after vascular endothelial cell injury. ${ }^{53}$ Tube formation of ECs is a key step in angiogenesis. ${ }^{54}$ Of factors influencing angiogenesis, the ionic microenvironment plays an important role. Mao et al found that the synergistic participation of $\mathrm{Sr}$ and $\mathrm{Si}$ ions is beneficial for promoting osteoporotic bone regeneration by regulating the behaviors of osteoblasts and osteoclasts as well as angiogenesis, where this effect is dependent on the concentrations of both ions. ${ }^{19}$ Therefore, HUVECs was selected as model to evaluate the angiogenic activity of the surface-coated Ti disks, and the leach liquors of the samples were used for cell culture. For the ED coating, both the Si doping and the nanosheet topography facilitated the release of $\mathrm{Ca}$ and $\mathrm{P}$ ions from the coating owing to decreased crystallinity (Figure 1C). Our results show that in the presence of various leach liquors, the HUVECs exhibited good cell growth and viability (Figure 6A and B). After culturing with the leach liquors, satisfactory migration and tube formation of the HUVECs were observed in all the experimental groups (Figures 6C and 7A), and the ranking was in the order HS-PC $>$ HS$\mathrm{CV}>$ HA-PC $>$ HA-CV (Figure 6D). However, both HS groups showed greater tube formation than both HA groups, and no significant difference was observed between HS-PC and HS-CV (Figure 7B).

VEGF and bFGF are widely considered to be important angiogenic growth factors that play a key role in stimulating vascularization during bone healing. ${ }^{55}$ Some studies have shown that the angiogenesis of HUVECs can be enhanced by the material-stimulated secretion of angiogenic factors in the HUVECs as an autocrine effect. ${ }^{56,57}$ $\mathrm{NO}$ is known as an important messenger molecule that not only participates in regulating a series of physiological activities of the body, but also features vascularization. ${ }^{58}$ Ang-1 is an angiopoietin that can phosphorylate the tyrosine kinase receptor on the endothelium and affect the synthesis of substances in the endothelium. ${ }^{59}$ However, compared with the control, no experimental group upregulated the gene expression of Ang-1.

HS-PC had a better effect on angiogenesis than HS-CV. No significant difference in the release of $\mathrm{Si}$ ions was found between HS-PC and HS-CV, where this can be ascribed to the release of more $\mathrm{Ca}$ and $\mathrm{P}$ ions in HS-PC than HS-CV. The released $\mathrm{Ca}$ and $\mathrm{P}$ ions synergistically promoted the migration of HUVECs and expressions of angiogenesis-related genes. Because it was only available in the HS samples, the key role of $\mathrm{Si}$ ion release from the coating in promoting angiogenesis was confirmed, which is in accordance with previous reports. ${ }^{60}$ Chen et al compared the angiogenic ability of porous calcium phosphate $(\mathrm{CaP})$ ceramics with different phasic compositions, and found that the $\mathrm{CaP}$ ceramic with higher $\beta$-TCP content, and thus a higher release of $\mathrm{Ca}$ and $\mathrm{P}$ ions, is more favorable for promoting in vitro and in vivo angiogenesis. ${ }^{56}$ This study has shown that both Si doping and coating topography can help improve material-mediated osteogenesis and angiogenesis. Thus, fabricating a specially designed ED coating on orthopedic Ti implants can enhance their angiogenic and osteogenic activities. However, this requires further verification in subsequent in vivo experiments.

\section{Conclusions}

The results of this study indicate that by using the ED method with the PC or CV mode, an HA nanocoating with high Si doping and morphological regulation on the surface of Ti can be easily achieved by adjusting the processing parameters. The surface properties of the coating are influenced by the Si doping and coating topography, and lead to changes in bioactivity. Compared with the nanorod or pure HA coating, the nanosheet or HS coating exhibited quicker apatite deposition and higher BSA adsorption capacity. In vitro cellular experiments proved that HS-PC with 0.8 wt.\% of Si content and nanosheet topography is more conductive to the spreading and osteoblastic differentiation of MC3T3-E1 pre-osteoblasts than the other three coatings examined. It also had the best effect in terms of promoting migration, tube formation, and angiogenesis-related gene expressions in HUVECs. The results show the potential of HS-PC in stimulating angiogenesis and osteogenesis, indicating that it can improve the bone regeneration and vascularization of orthopedic Ti implants.

\section{Acknowledgments}

This work was financially supported by the National Natural Science Foundation of China (81671825) and the Sichuan Science and Technology Innovation Team of China (2019JDTD0008).

\section{Disclosure}

The authors report no conflicts of interest in this work.

\section{References}

1. Kaur M, Singh K. Review on titanium and titanium based alloys as biomaterials for orthopaedic applications. Mater Sci Eng C. 2019;102:844-862. doi:10.1016/j.msec.2019.04.064 
2. Kokubo T, Kim H-M, Kawashita M. Novel bioactive materials with different mechanical properties. Biomaterials. 2003;24(13):2161-2175. doi:10.1016/S0142-9612(03)00044-9

3. Hanawa T, Asami K, Asaoka K. Surface, repassivation of titanium and surface oxide film regenerated in simulated bioliquid. $J$ Biomed Mater Res. 1998;40(4):530-538. doi:10.1002/(SICI)1097-4636(19980615)40:4<530::AID-JBM3>3.0.CO;2-G

4. Landor I, Vavrik P, Sosna A, et al. Hydroxyapatite porous coating and the osteointegration of the total hip replacement. Arch Orthop Traum Surg. 2007;127(2):81-89. doi:10.1007/s00402-006-0235-1

5. Goyenvalle E, Aguado E, Nguyen JM, et al. Osteointegration of femoral stem prostheses with a bilayered calcium phosphate coating. Biomaterials. 2006;27(7):1119-1128. doi:10.1016/j.biomaterials.2005.07.039

6. Tan G, Zhou L, Ning C, et al. Biomimetically-mineralized composite coatings on titanium functionalized with gelatin methacrylate hydrogels. Appl Surf Sci. 2013;279:293-299. doi:10.1016/j. apsusc. 2013.04.088

7. Ergun Y, Baspinar MS. Effect of acid passivation and H-2 sputtering pretreatments on the adhesive strength of sol gel derived Hydroxyapatite coating on titanium surface. Int J Hydrog Energy. 2017;42(32):20420-20429. doi:10.1016/j.ijhydene.2017.06.051

8. Askari N, Yousefpour M, Rajabi M. Electrochemical and biological characterization HA/A12 O3 -YSZ nano-composite coatings using electrophoretic process. J Biomed Mater Res A. 2018;106 (7):1916-1922. doi:10.1002/jbm.a.36392

9. Metoki N, Leifenberg-Kuznits L, Kopelovich W, et al. Hydroxyapatite coatings electrodeposited at near-physiological conditions. Mater Lett. 2014;119:24-27. doi:10.1016/j.matlet.2013. 12.091

10. Maleksaeedi S, Wang JK, El-Hajje A, et al. Toward 3D printed bioactive titanium scaffolds with bimodal pore size distribution for bone ingrowth. Procedia CIRP. 2013;5:158-163. doi:10.1016/j. procir.2013.01.032

11. Lee K, Jeong YH, Ko YM, et al. Hydroxyapatite coating on micropore-formed titanium alloy utilizing electrochemical deposition. Thin Solid Films. 2013;549:154-158. doi:10.1016/j. tsf.2013.09.002

12. Wang J, Wang M, Chen F, et al. Nano-hydroxyapatite coating promotes porous calcium phosphate ceramic-induced osteogenesis via BMP/Smad signaling pathway. Int J Nanomed. 2019;14:7987-8000. doi:10.2147/IJN.S216182

13. Zhao R, Chen SY, Yuan B, et al. Healing of osteoporotic bone defects by micro-/nano-structured calcium phosphate bioceramics. Nanoscale. 2019;11(6):2721-2732. doi:10.1039/C8NR09417A

14. Saran U, Gemini Piperni S, Chatterjee S. Role of angiogenesis in bone repair. Arch Biochem Biophys. 2014;561:109-117. doi:10.1016/ j.abb.2014.07.006

15. Santos MI, Reis RL. Vascularization in bone tissue engineering: physiology, current strategies, major hurdles and future challenges. Macromol Biosci. 2010;10(1):12-27. doi:10.1002/mabi.200900107

16. Lei T, Zhang W, Qian H, et al. Silicon-incorporated nanohydroxyapatite-reinforced poly( $\varepsilon$-caprolactone) film to enhance osteogenesis for bone tissue engineering applications. Colloid Surface B. 2020;187:110714. doi:10.1016/j.colsurfb.2019.110714

17. Huang Y, Wu C, Zhang X, et al. Regulation of immune response by bioactive ions released from silicate bioceramics for bone regeneration. Acta Biomater. 2018;66:81-92. doi:10.1016/j.actbio. 2017.08.044

18. Li H, Xue K, Kong N, et al. Silicate bioceramics enhanced vascularization and osteogenesis through stimulating interactions between endothelia cells and bone marrow stromal cells. Biomaterials. 2014;35(12):3803-3818. doi:10.1016/j.biomaterials.2014.01.039

19. Mao L, Xia L, Chang J, et al. The synergistic effects of $\mathrm{Sr}$ and $\mathrm{Si}$ bioactive ions on osteogenesis, osteoclastogenesis and angiogenesis for osteoporotic bone regeneration. Acta Biomater. 2017;61:217-232. doi:10.1016/j.actbio.2017.08.015
20. Chen $\mathrm{H}$, Wang $\mathrm{C}$, Yang $\mathrm{X}$, et al. Construction of surface $\mathrm{HA} / \mathrm{TiO}_{2}$ coating on porous titanium scaffolds and its preliminary biological evaluation. Mater Sci Eng C. 2017;70:1047-1056. doi:10.1016/j. msec.2016.04.013

21. Chen H, Wang C, Zhu X, et al. Fabrication of porous titanium scaffolds by stack sintering of microporous titanium spheres produced with centrifugal granulation technology. Mater Sci Eng C. 2014;43:182-188. doi:10.1016/j.msec.2014.07.026

22. Sze A, Erickson D, Ren L, et al. Zeta-potential measurement using the Smoluchowski equation and the slope of the current-time relationship in electroosmotic flow. $J$ Colloid Interface Sci. 2003;261 (2):402-410. doi:10.1016/S0021-9797(03)00142-5

23. Kokubo T, Takadama H. How useful is SBF in predicting in vivo bone bioactivity? Biomaterials. 2006;27(15):2907-2915. doi:10.10 16/j.biomaterials.2006.01.017

24. Li DH, Lin J, Lin D-Y, et al. Synthesized silicon-substituted hydroxyapatite coating on titanium substrate by electrochemical deposition. J Mater Sci: Mater Med. 2011;22(5):1205-1211. doi:10.1007/s10856011-4310-y

25. Zhang E, Zou C. Porous titanium and silicon-substituted hydroxyapatite biomodification prepared by a biomimetic process: characterization and in vivo evaluation. Acta Biomater. 2009;5(5):1732-1741. doi:10.1016/j.actbio.2009.01.014

26. Hing KA, Revell PA, Smith N, et al. Effect of silicon level on rate, quality and progression of bone healing within silicate-substituted porous hydroxyapatite scaffolds. Biomaterials. 2006;27(29):5014-5026. doi:10.1016/j.biomaterials.2006.05.039

27. Jeong YH, Choe HC. Electrochemical deposition of $\mathrm{Si}-\mathrm{Ca} / \mathrm{P}$ on nanotube formed beta $\mathrm{Ti}$ alloy by cyclic voltammetry method. J Nanosci Nanotechnol. 2015;15(8):6124-6128. doi:10.1166/jnn. 2015.10454

28. Chen X, Wu T, Wang Q, et al. Shield effect of silicate on adsorption of proteins onto silicon-doped hydroxyapatite (100) surface. Biomaterials. 2008;29(15):2423-2432. doi:10.1016/j.biomaterials. 2008.02.002

29. Tang XL, Xiao XF, Liu RF. Structural characterization of silicon-substituted hydroxyapatite synthesized by a hydrothermal method. Mater Lett. 2005;59(29-30):3841-3846. doi:10.1016/j. matlet.2005.06.060

30. Gibson IR, Best SM, Bonfield W. Chemical characterization of silicon-substituted hydroxyapatite. J Biomed Mater Res. 1998;44 (4):422-428.

31. Andersson J, Areva S, Spliethoff B, et al. Sol-gel synthesis of a multifunctional, hierarchically porous silica/apatite composite. Biomaterials. 2005;26(34):6827-6835. doi:10.1016/j.biomaterials. 2005.05.002

32. Wang J, Chen X, Guo B, et al. A serum protein adsorption profile on BCP ceramics and influence of the elevated adsorption of adhesive proteins on the behaviour of MSCs. J Mater Chem B. 2018;6 (45):7345-7558. doi:10.1039/C8TB02283F

33. Zhu X, Fan H, Li D, et al. Protein adsorption and zeta potentials of a biphasic calcium phosphate ceramic under various conditions. $J$ Biomed Mater Res B. 2007;82B(1):65-73. doi:10.1002/jbm. b.30706

34. Fujii E, Ohkubo M, Tsuru K, et al. Selective protein adsorption property and characterization of nano-crystalline zinc-containing hydroxyapatite. Acta Biomater. 2006;2(1):69-74. doi:10.1016/j. actbio.2005.09.002

35. Deligianni DD, Katsala N, Ladas S, et al. Effect of surface roughness of the titanium alloy Ti-6Al-4V on human bone marrow cell response and on protein adsorption. Biomaterials. 2001;22(11):1241-1251. doi:10.1016/S0142-9612(00)00274-X

36. Chen $\mathrm{S}$, Wang X, Gao S, et al. Effects of hydrogenated $\mathrm{TiO}_{2}$ nanotube arrays on protein adsorption and compatibility with osteoblast-like cells. Clin Oral Implant Res. 2018;13:2037-2049. 
37. Yoo YW, Lee W-K. Modification of silica surface with nonstoichiometric calcium phosphate and its effects on protein adsorption and osteoblast response. Surf Coat Technol. 2012;213:291-298. doi:10.1016/j.surfcoat.2012.10.073

38. Thian ES, Huang J, Best SM, et al. Silicon-substituted hydroxyapatite: the next generation of bioactive coatings. Mater Sci Eng C. 2007;27(2):251-256. doi:10.1016/j.msec.2006.05.016

39. Chen XB, Li Y-C, Plessis JD, et al. Influence of calcium ion deposition on apatite-inducing ability of porous titanium for biomedical applications. Acta Biomater. 2009;5(5):1808-1820. doi:10.1016/j. actbio.2009.01.015

40. Wang X, Zhou Y, Xia L, et al. Fabrication of nano-structured calcium silicate coatings with enhanced stability, bioactivity and osteogenic and angiogenic activity. Colloid Surface B. 2015;126:358-366. doi:10.1016/j.colsurfb.2014.11.044

41. Chen CY, Ozasa K, Katsumata KI, et al. Bioactive titanium oxide-based nanostructures prepared using one-step hydrothermal anodization method. J Phys Chem C. 2012;116(14):8054-8062. doi:10.1021/jp210783w

42. Wang $\mathrm{H}$, Zhang XR, Wang $\mathrm{HC}$, et al. Enhancing the osteogenic differentiation and rapid osseointegration of 3D printed Ti6Al4V implants via nano-topographic modification. J Biomed Nanotechnol. 2018;14(4):707-715. doi:10.1166/jbn.2018.2551

43. $\mathrm{Hu} \mathrm{ZK}$, Wang XH, Xia W, et al. Nano-structure designing promotion osseointegration of hydroxyapatite coated Ti-6Al-4V alloy implants in diabetic model. J Biomed Nanotechnol. 2019;15(8):1701-1713. doi:10.1166/jbn.2019.2812

44. Wang L, He S, Wu X, et al. Polyetheretherketone/nanofluorohydroxyapatite composite with antimicrobial activity and osseointegration properties. Biomaterials. 2014;35(25):6758-6775. doi:10.1016/j.biomaterials.2014.04.085

45. Varanasi VG, Leong KK, Dominia LM, et al. Si and Ca individually and combinatorially target enhanced MC3T3-E1 subclone 4 early osteogenic marker expression. J Oral Implantol. 2012;38 (4):325-336. doi:10.1563/AAID-JOI-D-11-00108

46. Kim EJ, Bu SY, Sung MK, et al. Effects of silicon on osteoblast activity and bone mineralization of MC3T3-E1 cells. Biol Trace Elem Res. 2013;152(1):105-112. doi:10.1007/s12011-012-9593-4

47. Frank O, Heim M, Jakob M, et al. Real-time quantitative RT-PCR analysis of human bone marrow stromal cells during osteogenic differentiation in vitro. $J$ Cell Biochem. 2002;85(4):737-746. doi:10.1002/jcb.10174

48. Amaral M, Costa MA, Lopes MA, et al. $\mathrm{Si}_{3} \mathrm{~N}_{4}$-bioglass composites stimulate the proliferation of MG63 osteoblast-like cells and support the osteogenic differentiation of human bone marrow cells. Biomaterials. 2002;23(24):4897-4906. doi:10.1016/S0142-9612(02)00249-1
49. Liu S, Jin FC, Lin KL, et al. The effect of calcium silicate on in vitro physiochemical properties and in vivo osteogenesis, degradability and bioactivity of porous $\beta$-tricalcium phosphate bioceramics. Biomed Mater. 2013;8(2):025008. doi:10.1088/1748-6041/8/2/ 025008

50. Liu L, Wang XH, Zhou YN, et al. The synergistic promotion of osseointegration by nanostructure design and silicon substitution of hydroxyapatite coatings in a diabetic model. J Mater Chem B. 2020;8 (14):2754-2767. doi:10.1039/C9TB02882J

51. Chim SM, Tickner J, Chow ST, et al. Angiogenic factors in bone local environment. Cytokine Growth Factor Rev. 2013;24 (3):297-310. doi:10.1016/j.cytogfr.2013.03.008

52. He X, Rosemary D, Xue Y, et al. BMP2 genetically engineered MSCs and EPCs promote vascularized bone regeneration in rat critical-sized calvarial bone defects. PLoS One. 2013;8(4):e60473. doi:10.1371/ journal.pone.0060473

53. Li HY, He J, Yu HF, et al. Bioglass promotes wound healing by affecting gap junction connexin 43 mediated endothelial cell behavior. Biomaterials. 2016;84:64-75. doi:10.1016/j. biomaterials.2016.01.033

54. Vandekeere S, Dewerchin M, Carmeliet P. Angiogenesis revisited: an overlooked role of endothelial cell metabolism in vessel sprouting. Microcirculation. 2015;22(7):509-517. doi:10.1111/micc.12229

55. Endler A, Chen L, Li Q, et al. Int6/eIF3e silenced HIF2 $\alpha$ stabilization enhances migration and tube formation of HUVECs via IL-6 and IL8 signaling. Cytokine. 2013;62(1):115-122. doi:10.1016/j. cyto.2013.01.021

56. Chen Y, Wang J, Zhu XD, et al. Enhanced effect of $\beta$-tricalcium phosphate phase on neovascularization of porous calcium phosphate ceramics: in vitro and in vivo evidence. Acta Biomater. 2015;11:435-448. doi:10.1016/j.actbio.2014.09.028

57. Li H, Chang J. Stimulation of proangiogenesis by calcium silicate bioactive ceramic. Acta Biomater. 2013;9(2):5379-5389. doi:10.1016/j.actbio.2012.10.019

58. Long BV, Bui TQ, Tomita T. Novel angiogenesis therapeutics by redox injectable hydrogel - Regulation of local nitric oxide generation for effective cardiovascular therapy. Biomaterials. 2018;167:143-152. doi:10.1016/j.biomaterials.2018.03.023

59. Li H, Chang J. Bioactive silicate materials stimulate angiogenesis in fibroblast and endothelial cell co-culture system through paracrine effect. Acta Biomater. 2013;9(6):6981-6991. doi:10.1016/j.actbio. 2013.02.014

60. Day RM. Bioactive glass stimulates the secretion of angiogenic growth factors and angiogenesis in vitro. Tissue Eng. 2005;11(5-6):768-777. doi:10.1089/ten.2005.11.768
International Journal of Nanomedicine

\section{Publish your work in this journal}

The International Journal of Nanomedicine is an international, peerreviewed journal focusing on the application of nanotechnology in diagnostics, therapeutics, and drug delivery systems throughout the biomedical field. This journal is indexed on PubMed Central, MedLine, CAS, SciSearch ${ }^{\mathbb{R}}$, Current Contents ${ }^{\mathbb{B}} /$ Clinical Medicine,
Journal Citation Reports/Science Edition, EMBase, Scopus and the Elsevier Bibliographic databases. The manuscript management system is completely online and includes a very quick and fair peer-review system, which is all easy to use. Visit http://www.dovepress.com/ testimonials.php to read real quotes from published authors. 